\title{
Using the Pressure Chamber for Irrigation Management in Walnut, Almond, and Prune
}

\section{INTRODUCTION}

-his publication describes how a pressure chamber is used to measure midday stem water potential (SWP) and how that information is used to guide irrigation scheduling decisions for walnut, almond, and prune. When used correctly, the pressure chamber can help growers and consultants save water, reduce irrigation costs, improve growth in developing orchards, and sustain higher levels of crop productivity while reducing tree loss and increasing orchard life span.

\begin{tabular}{|c|c|c|}
\hline \multicolumn{3}{|l|}{ CONTENTS } \\
\hline 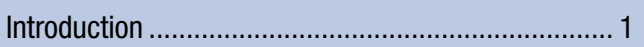 & Pressure Chamber Operation and Measurement & How Is SWP Influenced by Other Orchard \\
\hline How Water Moves in Trees: The Soil-Plant- & 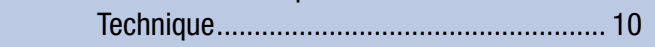 & Variables? \\
\hline Atmospheric Continuum .................................. & Accessories and Suggestions for Measuring & Too Much or Too Little Water .................................. 23 \\
\hline Ising the Prescure Chamber and Stem Water. & SWP Efficiently ............................................. 12 & 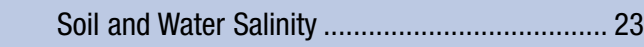 \\
\hline $\begin{array}{l}\text { Using the Pressure Cnamber and stem water } \\
\text { Potential in Orchards }\end{array}$ & Specific Guidelines for Interpreting SWP & Fruit or Nut Set (Crop Load).............................. 23 \\
\hline Potentlal in Urchards .......................................... 5 & Measurements and Scheduling Irrigations in Walnut. & Soil Fertility and Plant Nutrition ........................ 23 \\
\hline $\begin{array}{l}\text { Choosing a Pressure Chamber .......................... } 5 \\
\text { Pressure Chamber Safety.................................. } 5\end{array}$ & 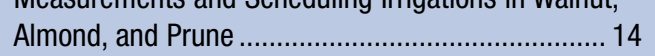 & Tree Diseases............................................... 24 \\
\hline 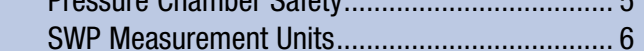 & Using SWP in Walnut Irrigation .............................. 14 & Other Pests.. \\
\hline Time of Day and Frequency of SWP & Research Basis for Walnut Guidelines ............... 15 & Rootstocks and Cultivars........................................ 24 \\
\hline 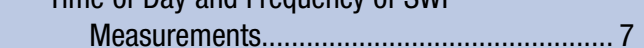 & Using SWP in Almond Irrigation ......................... 17 & Orchard Canopy Management.............................. 24 \\
\hline Selecting Trees to Measure SWP: & Research Basis for Almond Guidelines .............. 18 & SWP: Stand-Alone or Complementary Irrigation \\
\hline 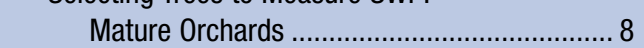 & Applying SWP in Prunes .................................. 20 & Management Tool? ………………………......... \\
\hline Selecting Trees to Measure SWP: & Research Basis for Prune Guidelines................... 20 & 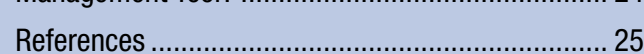 \\
\hline 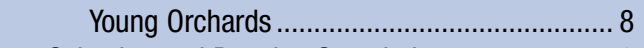 & Using Baseline Predictions to Interpret Orchard & \\
\hline Selecting and Bagging Sample Leaves................. 9 & 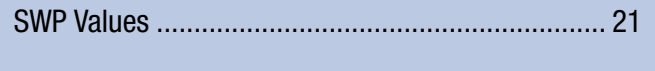 & 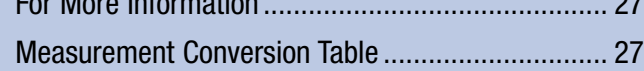 \\
\hline
\end{tabular}

ALLAN FULTON, UC Cooperative Extension Farm Advisor, Tehama County; JOE GRANT, UC Cooperative Extension Farm Advisor, San Joaquin County; RICHARD BUCHNER, UC Cooperative Extension Farm Advisor, Tehama County; and JOE CONNELL, UC Cooperative Extension Farm Advisor, Butte County 
The challenge for irrigation managers is to determine when to irrigate and how much water to apply. The two methods typically used to make these determinations are the water budget approach and soil moisture monitoring.

The water budget technique relies on weather conditions to estimate tree water use. Irrigations are applied to replace water lost from soil evaporation and plant transpiration. The sum of these two processes is evapotranspiration (ET). A water budget accounts for the influence of variable weather on crop water demand. Accuracy depends on adjustments for orchard canopy architecture and the amount of light intercepted by the leaf area. Irrigation decisions also

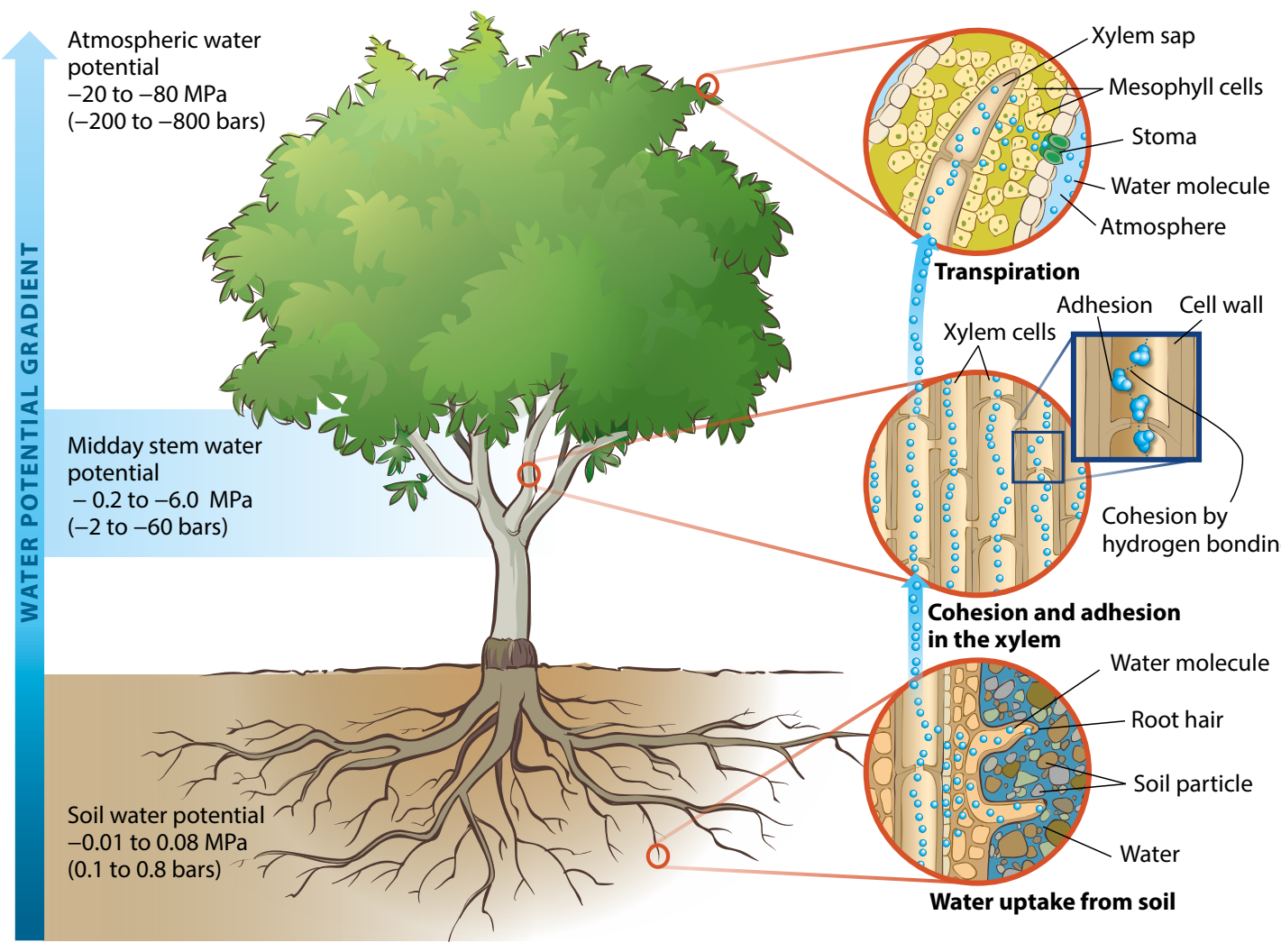

Figure 1. Conceptual illustration of how water moves from the soil through an irrigated tree and into the atmosphere, from both a whole tree and cellular perspective. SWP measures the water-potential gradient that drives this movement of water through the tree. Source: Adapted from Pearson 2008. depend on the amount of soil moisture stored from winter rainfall and effective in-season precipitation. Soil moisture monitoring characterizes the moisture conditions in the root zone by indicating the depth of water infiltration from irrigation and rainfall and the amount of soil moisture depletion from tree uptake. Soil moisture can be estimated by the appearance and "feel" of soil at various depths or with one of a variety of available sensors developed for this purpose. Proper hand probing of the soil or sensor placement in the root zone, along with an understanding of the water retention and release characteristics of specific soil types, are critical to providing information that accurately reflects changing conditions in the orchard.

A water budget approach plus soil-based monitoring can provide objective, accurate, and useful information for scheduling orchard irrigations, but these methods indirectly measure actual ET and tree water status. For many decades scientists have worked to develop a direct method to measure plant water status. The pressure chamber was developed originally for research purposes as a device to understand water movement in plants (Scholander et al. 1965). It has been effectively used to understand plant-water relations in forest systems (Waring and Cleary 1967) and in annual agricultural crops (Grimes and Yamada 1982). Since the 1980s scientists have developed techniques to use the pressure chamber in orchard crops to provide direct measurement of tree water status as it responds to the soil-plant-atmospheric continuum (McCutchan and Shackel 1992; Goldhamer and Fereres 2001). Relationships have been established between pressure chamber measurements and tree growth and productivity. From these relationships, guidelines have been developed to assist growers in making irrigation scheduling decisions using pressure chamber measurements.

\section{How Water Moves in Trees: The Soll-Plant- Atmospheric ContinuUm}

During plant transpiration, water moves from the soil into fine root tips, up through the vascular system, and out into the atmosphere (fig. 1). Water flows through the tree from high potential in the 
soil (about -10 centibars or -0.1 bar) to low potential in the atmosphere (less than -40 bars). Low potential is created at the leaf surface through small openings called stomata that open and close to regulate photosynthesis, gas exchange, and plant water loss. Simultaneously, water held in the soil enters root tissue and begins its journey to the leaves. This creates a vacuum or tension within the water-conducting system of the tree. The amount of tension depends on the balance between available soil moisture and the rate at which water is transpired from leaves.

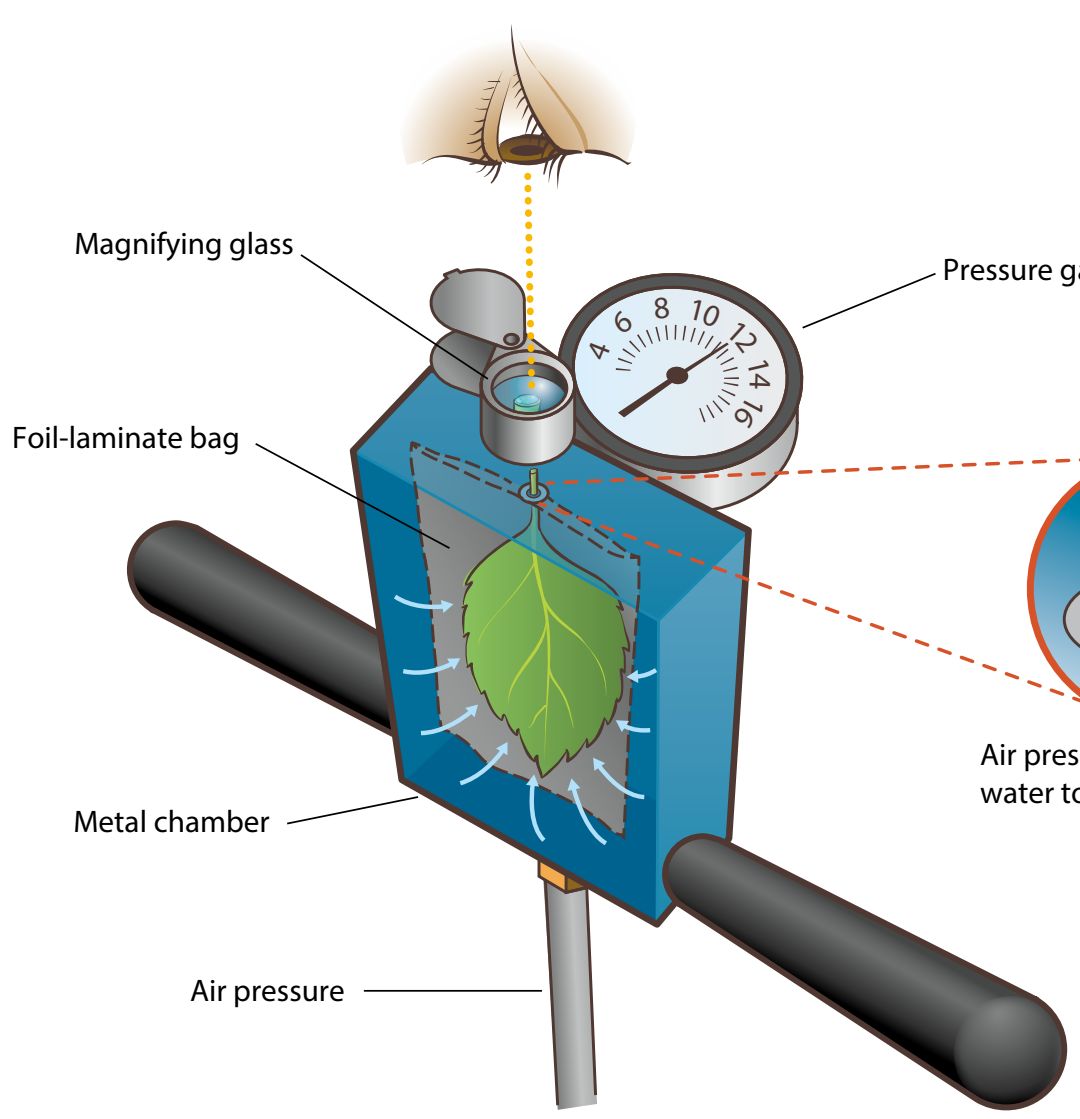

Figure 2. Schematic showing how water potential is measured in a severed leaf and stem (petiole) using a handheld pump-up pressure chamber. Source: Adapted from Plant Moisture Stress (PMS) Instrument Company.
A pressure chamber measures plant water tension by applying pressure to a severed leaf and stem enclosed in an airtight chamber. The pressure required to force water out of the stem of a severed leaf equals the water potential and is measured by an external pressure gauge (fig. 2). As soil moisture is depleted, more tension develops in the plant, requiring more pressure to force water out of the cut surface of the leaf stem.

As water evaporates through open stomates, carbon dioxide $\left(\mathrm{CO}_{2}\right)$ enters the intercellular air spaces within the leaf. Photosynthesis captures the sun's energy and acquires carbon to produce sugars and carbohydrates, which are the building blocks for tree growth and fruit and nut development. Plants gain carbon at the expense of water loss. Because tree water status affects the opening and closing of stomates to capture carbon, there is a strong relationship between water stress and tree growth and productivity.

Over the years, scientists have studied several ways to use the pressure chamber to measure water potential as an indicator of orchard water status. Each technique is similar, but they have important differences that affect the measurement. Techniques include

- leaf water potential

- predawn leaf water potential

- stem water potential (SWP)

- shaded leaf water potential

The leaf water potential technique uses a bare or uncovered leaf for measurements. This technique was used when the pressure chamber was first introduced. Leaf water potential is usually measured midafternoon when plant tension is greatest. Scientists have shown leaf water potential to be useful as an irrigation scheduling tool in wine grapes and cotton (Grimes and Yamada 1982; Williams and Araujo 2002). Other researchers have shown that leaf water potential may not be a reliable indicator of plant water status, particularly for mature trees with larger canopies (Bates and Hall 1981; Jones 1985; McCutchan and Shackel 1992). Leaf water potential is often highly variable among different leaves on the same tree. Measurements are variable because each leaf experiences 
differences in light exposure and temperature. Bare leaves also desiccate more rapidly after they are excised from the tree, causing additional variation in leaf water potential measurements (Turner and Long 1980; Garnier and Berger 1985; Olien and Lakso 1986).

Predawn leaf water potential also uses a bare or uncovered leaf to measure tree water status. Predawn measurements are made in the dark before sunrise. Working in such conditions is inconvenient and requires a flashlight to operate the pressure chamber and navigate the orchard. But scientists prefer predawn because it minimizes variations due to light exposure and temperature issues associated with daytime readings. Predawn

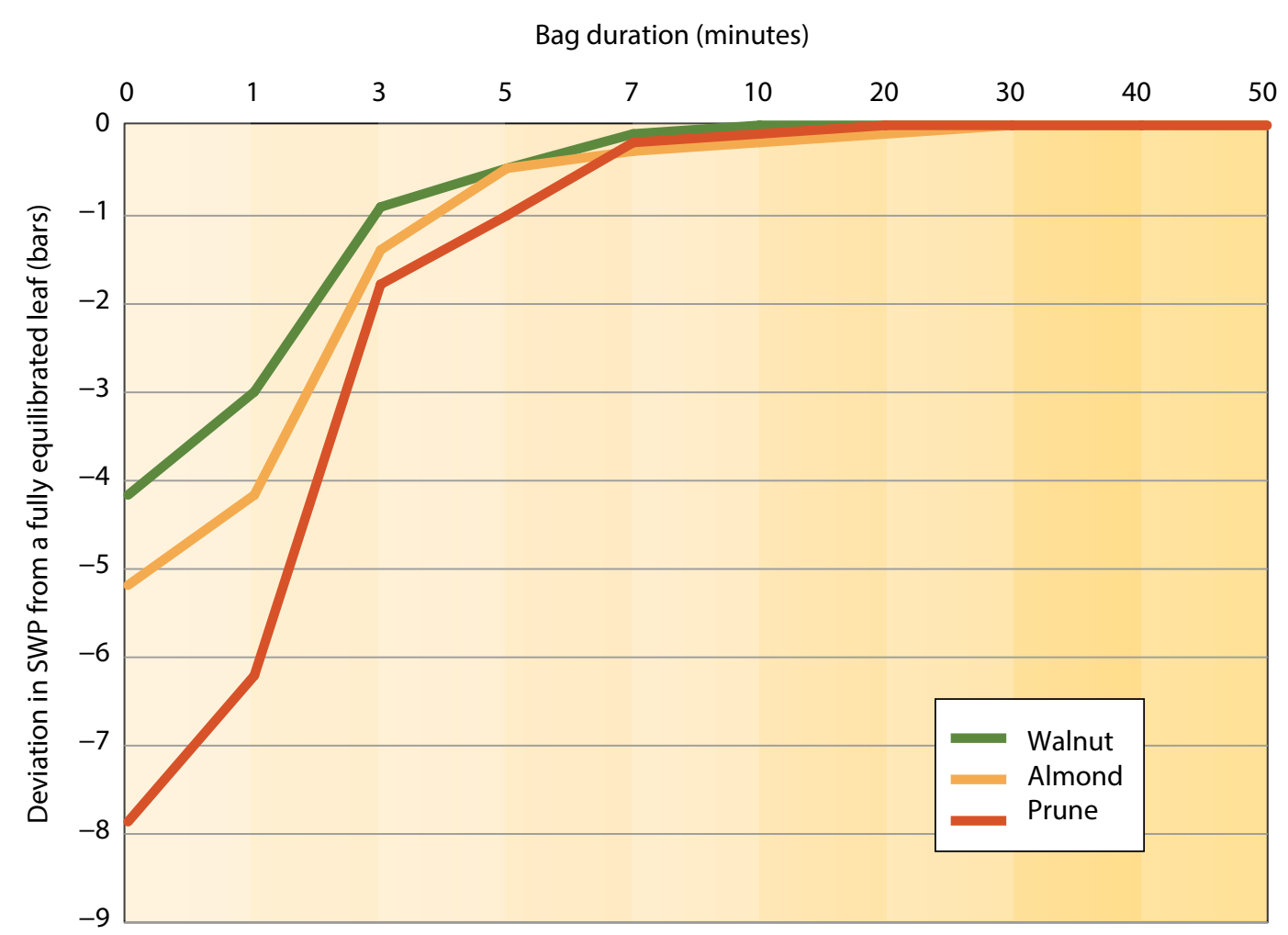

Figure 3. Response of SWP to the amount of time an almond, prune, or walnut leaf is covered by a reflective bag to prevent leaf transpiration. Source: Adapted from Fulton et al. 2001. measurements reflect tree water status after trees have recovered from the previous day's environment and not during the period of maximum water demand at midday. When used in orchards irrigated with drip and microsprinklers, the predawn leaf water potential may be less sensitive to gradual soil moisture depletion compared with techniques that incorporate the added stress of midday water movement in the tree (Ameglio et al. 1999).

Stem water potential (SWP) is measured midday from 12:00 to 4:00 p.m. The idea is to make measurements when the tree is experiencing relatively constant and maximum water demand. To measure SWP, a leaf from the lower shaded canopy is placed inside a foil bag ("bagged") for about 10 minutes before it is cut from the tree branch and placed into the pressure chamber. Bagging the leaf eliminates photosynthesis and water loss so the leaf reaches equilibrium with the water-conducting system of the adjacent branches and trunk (McCutchan and Shackel 1992; Fulton et al. 2001). Stem water potential reduces the measurement variability associated with using bare leaves exposed to different amounts of light and heat, and it minimizes desiccation after leaves have been excised from the tree. Figure 3 illustrates how the water tension of a bare (unbagged) leaf quickly reaches equilibrium after being covered with a reflective bag. After a leaf is bagged, a rapid change takes place in its internal water status during the first 3 to 5 minutes. After 10 minutes, a bagged leaf reaches full equilibrium with the water-conducting system of the tree. At this point the water potential of the bagged leaf is stable and ready for measurement. If there is a practical advantage to doing so, you may also bag a leaf several hours in advance-or even overnight-and then return midday to measure SWP.

Shaded leaf water potential, like SWP, involves taking measurements in midafternoon when photosynthetic activity and water demand is highest. Instead of covering the leaf with a foil bag, a damp cloth is used to wrap the sample leaf, which is then immediately excised from the tree and placed in the pressure chamber while still wrapped in the damp cloth (Goldhamer and Fereres 2001). Shaded leaf water potential is a convenient and reliable technique, correlating with the SWP technique, although 


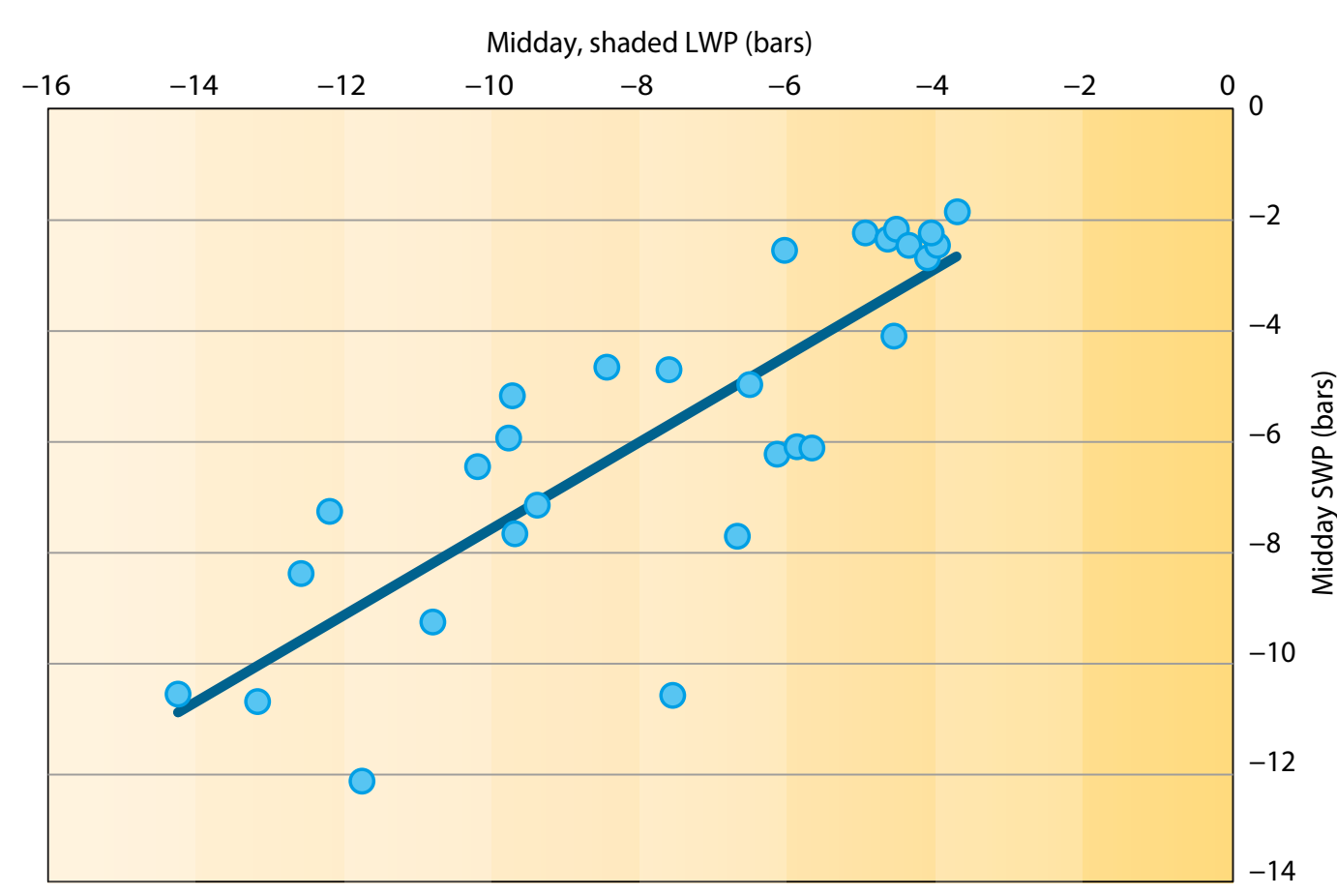

Figure 4. The relationship between stem water potential (SWP) and shaded leaf water potential (LWP) when used to monitor orchard water status for Chandler walnut. Source: Fulton et al. 2003.

shaded readings average about -1.0 to -2.0 bars more tension of crop stress compared with SWP (fig. 4). With additional research and experience, it is possible to fine-tune how orchard growth and production corresponds to shaded leaf values.

Most of the recent field research that correlates orchard water status to tree response and crop productivity has been done using the SWP method with bagged leaves. A relatively good knowledge base has been developed for using SWP to guide irrigation decisions in walnut, almond, and prune orchards, and SWP is gaining increasing on-farm acceptance and use. For these reasons, the remainder of this publication focuses on SWP using bagged leaves.

\section{Using the Pressure Chamber and Stem Water Potential in Orchards}

\section{Choosing a Pressure Chamber}

A number of companies produce durable, portable, and relatively inexpensive pressure chambers for measuring stem water potential (SWP). The choice of a pressure chamber depends largely on preferences. The cost may range from less than $\$ 1,000$ to about $\$ 7,000$, depending on the style, design, and whether the unit is new or used. Compressed nitrogen gas is a convenient, relatively inexpensive, and inert (safe) gas to use as a source of pressure. Air pressure requires a special pump to provide sufficient pressure. Most small, affordable air compressors cannot provide enough pressure. Approximately 300 to 400 psi or perhaps higher may be needed to measure stem water potential in almonds and prunes. Carbon dioxide gas is also used to supply pressure with some pressure chambers.

Several pressure chamber styles and designs are available, ranging from simple manual pump-ups to consoles with more advanced features (fig. 5). All have the same basic components and operate on the same concept. Basic components of a pressure chamber include an airtight chamber and locking lid to hold the sample leaf; a source of compressed air or nitrogen to provide pressure in the chamber; a control valve to pressurize and exhaust the chamber; a regulating valve or manual pump to control the rate at which the chamber is pressurized; and a gauge to display the pressure inside the chamber. Pressure chamber gauges vary in style. Both mechanical dial and electronic digital-style gauges are available. Though many of the components are readily available, and homemade pressure chambers have been constructed, this is not recommended. Commercially available pressure chambers have been tested for quality, safety, and accuracy, whereas homemade chambers are not. 

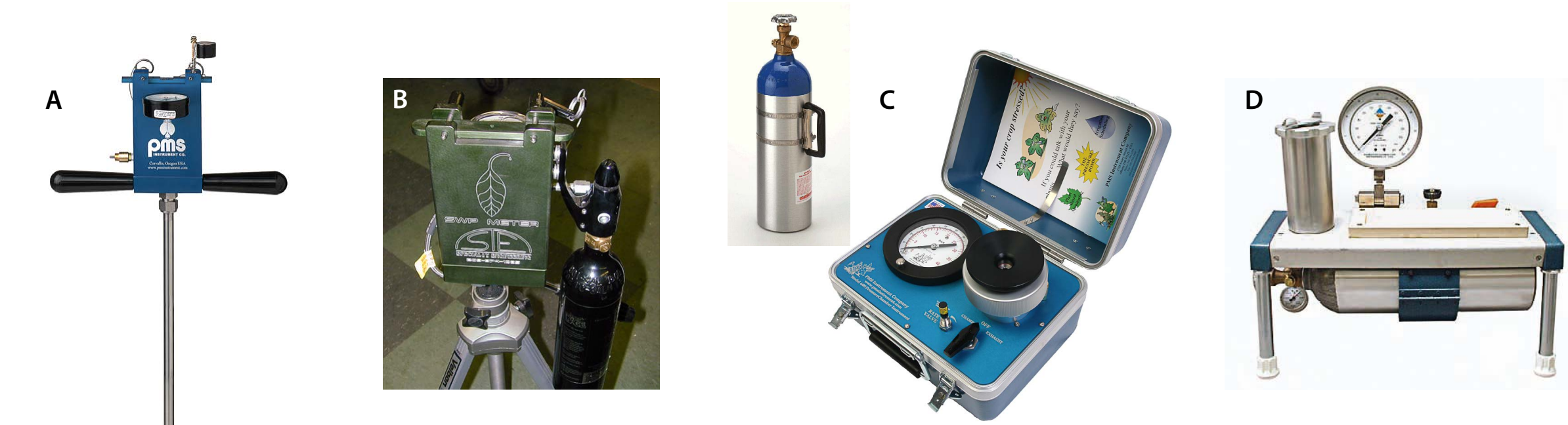

Figure 5. Four different examples of commercially available pressure chambers. Example $A$ is a pump-up style by PMS Instruments, in which a foot pump is used to create air pressure in the rectangular chamber. Example B by Specialty Engineering also has a rectangular chamber, employs a tripod to hold the pressure chamber, and uses compressed carbon dioxide $\left(\mathrm{CO}_{2}\right)$ gas to supply the pressure. Example $\mathrm{C}$ is a suitcase-style pressure chamber. It has a cylindrical chamber that uses an external source of nitrogen gas, stored in a metal cylinder, to pressurize the chamber. Both PMS Instruments and Soilmoisture Equipment Corp. offer this style of pressure chamber. Example D is a console- or bench-style pressure chamber by Soilmoisture Equipment Corp., which also uses an external bottle of nitrogen gas to pressurize the chamber. Photos: Courtesy of Plant Moisture Stress (PMS) Instrument Company, Albany, OR (A, C); Specialty Engineering, Waterford, CA (B); and Soilmoisture Equipment Corp., Santa Barbara, CA (D).

\section{Pressure Chamber Safety}

Pressure chambers are often referred to as "pressure bombs" because they are capable of containing very high chamber pressures. For example, an almond leaf with a -20 bars SWP endpoint, which is common during hull split and at harvest, is equivalent to 290 pounds per square inch (psi) of pressure. (For converting U.S. customary units to metric units, see the table at the end of this publication.) Almond and prune trees under high crop-water stress pressures can register over 500 psi of pressure inside the chamber. A chamber failure could be fatal when an operator is within inches or even feet of the pressurized chamber while operating and watching for the endpoint of the measurement. This is a very good reason not to attempt to build and use a homemade pressure chamber. Injury from operating a professionally manufactured pressure chamber is highly unlikely (unknown to the authors). Another safety concern is that on rare occasions the pressure inside the chamber has the potential to turn a broken leaf stem into a projectile that may shoot towards an operator's eye as the operator is watching for the endpoint of a measurement. Eye protection is required, and developing safe operational and observational techniques will greatly reduce this risk. Using a large magnifying glass to observe the endpoint will also help make it more visible from a greater distance and guard against eye injury.

\section{SWP Measurement Units}

The most common English unit of measurement for SWP is the bar. To appreciate the energy needed for water to move up a tree, one bar of tension equals 14.5 psi of pressure. Since the water in plants is under tension, or negative pressure, the scientific convention is to express SWP in negative values. So, a walnut tree with SWP of -4 bars is under less tension, or water stress, than a walnut tree with SWP of -10 bars. Mathematically, -4 is a larger number (less negative) compared with -10 (more negative). The gauge on a pressure chamber does not usually indicate negative numbers-so, for simplicity and convenience, a larger number on a pressure gauge indicates more tree stress. The most widely accepted international 
unit of measurement is the megapascal (MPa). Ten bars equal 1.0 megapascal.

In this publication the SWP measurements will be discussed (and presented in tables and figures) as negative values in bars, to be consistent with scientific convention used in other literature.

\section{Time of Day and Frequency of SWP Measurements}

SWP measurements are taken midafternoon (12:00 noon to 4:00 p.m.), when water demand and photosynthesis are greatest. Also, solar radiation, air temperature, and humidity-the main environmental factors that drive tree water use-are more stable during midafternoon. These two features tend to make SWP readings less variable and easier to interpret (fig. 6). SWP measurements can be made at any time of day and accurately reflect tree water potential at the time of measurement. From a practical standpoint, however, irrigation managers are interested in the

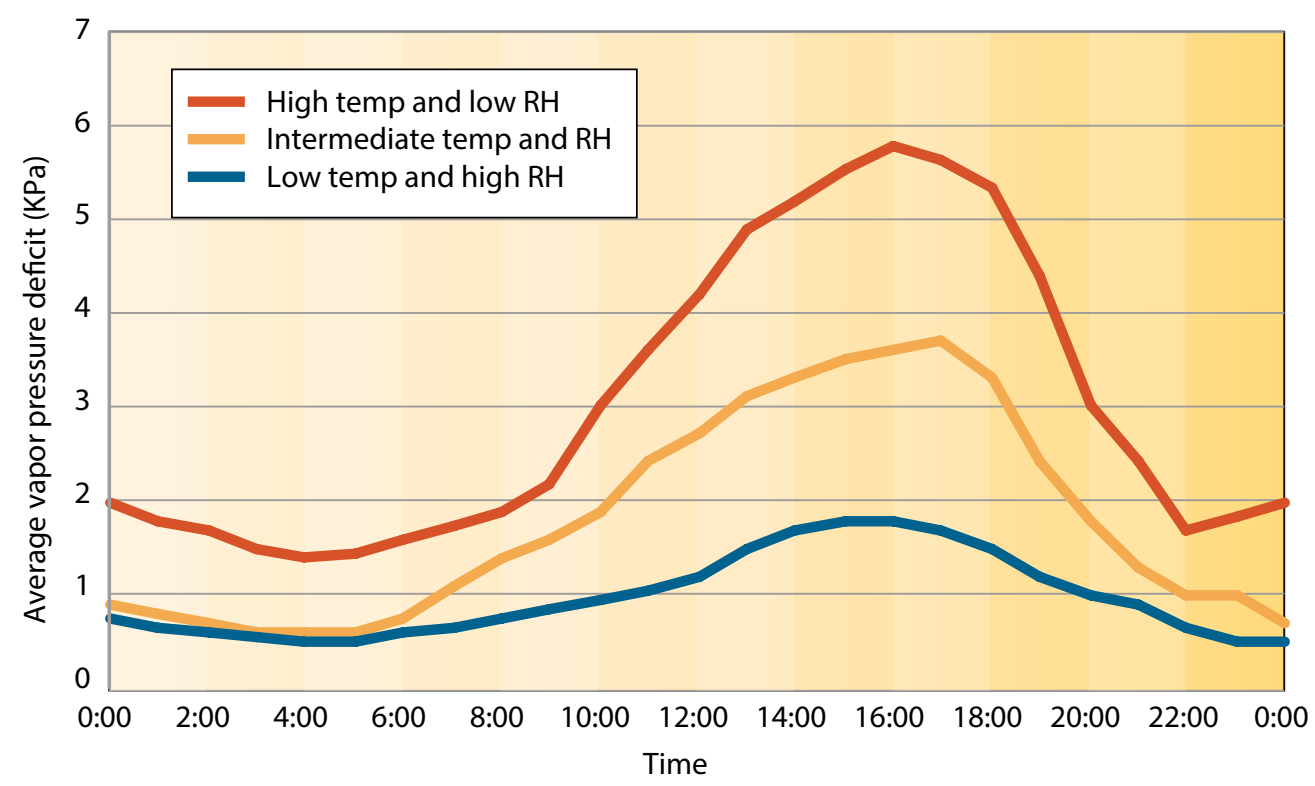

Figure 6. Variation in air vapor pressure deficit in an orchard is caused by hourly and daily variability of weather. The most stable periods of air vapor pressure deficit and the corresponding period for measuring water potential is predawn ( 3 a.m. to 5 a.m.) and midafternoon (12 noon to 4 p.m.). Source: Adapted from Fulton et al. 2001. highest stress that trees experience, which is at midday. Thus, the guidelines for interpreting SWP measurements have been made by using midday measurements.

SWP measurements should begin during the spring season and continue through the summer and fall. This approach will show how orchard water status responds to seasonal weather changes and how irrigation scheduling will need to be adapted. Postponing SWP measurements until early summer will miss the progressive changes in orchard water status leading up to the summer season (when water demand is highest).

How often measurements are taken depends on practical considerations. Orchard acreage, time availability, coordination with other tasks, and specific interests may influence measurement frequency. Most irrigation managers have found that measuring SWP just prior to irrigation and 1 or 2 days after irrigation provides the best information about the ongoing water status of the orchard. SWP measurements taken just before irrigation will indicate the orchard water status when soil moisture levels are the driest and orchard stress is potentially the highest. Monitoring SWP 1 or 2 days after irrigation will indicate how well the tree water status recovered after irrigation.

SWP may be measured daily or every other day between irrigations at different times during the year to understand how rapidly SWP measurements change. A concentrated effort like this may only be needed once in the spring and once in the summer between irrigations during the entire irrigation season. SWP measured in orchards growing on shallow soils with restricted root depth and less available water-holding capacity may change very rapidly, possibly -2 to -5 bars per day. Orchards growing in deep soils with a higher water-holding capacity and larger root systems may change SWP more slowly, maybe -0.3 to -1.0 bar per day. Understanding how quickly SWP changes in response to specific growing conditions and soil moisture depletion in orchards can aid in deciding how often measurements should be made.

SWP can also be measured on a routine schedule, such as weekly or every other week. A routine monitoring schedule lends itself to managing time and employees but is not as informative 
as specifically timing SWP just before and after irrigation. For example, if SWP measurements are taken routinely in the middle of the irrigation "off" interval, neither the greatest amount of tree stress just prior to irrigation nor the amount of recovery (least tree stress) just after irrigation will be measured. Measuring SWP on a routine schedule in orchards that are irrigated at least weekly with drip or microsprinklers, will, however, indicate whether the tree stress is approaching thresholds detrimental to tree growth and productivity or whether the trends in orchard water status are stable and within desirable levels. With flood, hand-move, or solidset sprinkler systems that provide larger applications of water less frequently (e.g., 2 to 3 weeks between irrigations), the timing of the SWP measurement in relation to irrigation is more critical. SWP measurements need to be taken often enough during these longer intervals to accurately indicate the full spectrum of tree stress that occurs.

The approach to monitoring frequency can be flexible. All orchards do not have to be monitored at the same time. Monitoring may be more intensive in an orchard that is under new management or in an orchard where tree growth, production, or tree health is of concern and troubleshooting is the objective. In other orchards with a history of SWP measurement or where there are no specific concerns, measurements may be made less frequently. Usually, when using a pressure chamber for the first time in an orchard, measurements are made more frequently. With more experience, the number of measurements can be reduced without sacrificing accuracy.

\section{Selecting Trees to Measure SWP: Mature Orchards}

Trees selected for SWP monitoring should be representative of the orchard. Good measurement trees would be of the same variety and rootstock, and similar in age, degree of pruning, and canopy size. Measurement trees should be irrigated in the same manner as the rest of the orchard and should be healthy. If a tree used for SWP monitoring develops disease symptoms midseason or some other injury (e.g., shaker injury), select a different tree.
The same trees should be used to measure SWP each time to reduce variation from one reading time to the next. The sample trees should be marked with flagging or spray paint or possibly identified using a handheld GPS device so they are easily relocated each time SWP measurements are made. It helps to flag the ends of rows where sample trees are located.

Determining how many trees to monitor must balance having enough trees to reliably represent the orchard and being able to cover the desired total acreage in a timely and efficient manner. Sampling fewer trees and accepting the possibility of less representative measurements is better than not using SWP at all because it is perceived as too labor-intensive. The number of trees to monitor in an orchard also depends on soil variability and irrigation uniformity. Fewer trees are needed if the orchard is growing on one predominant soil type with uniform irrigation. More trees are needed if there is more than one soil type and nonuniform irrigation. A sampling strategy that can be completed in about 30 to 60 minutes per orchard is ideal, especially if several orchards must be monitored on the same afternoon. Understanding of orchard water status will improve as the number of trees monitored is increased. A sample size ranging from 5 to 10 trees per orchard is probably optimal for achieving representative measurements and covering acreage efficiently. Measuring SWP in as few as three trees in an orchard will be more informative than not measuring SWP at all. Measurement trees must represent the other trees in the orchard. The trees selected for SWP measurement should be at least 100 feet inside the orchard and have other healthy trees growing around them for competition to avoid anomalies such as may occur by selecting trees along the edge of an orchard.

\section{Selecting Trees to Measure SWP: Young Orchards}

SWP is a very useful tool for assessing water status and irrigation needs of young orchards, possibly more valuable in young orchards than in mature trees. Young trees are growing rapidly, so the leaf area and root development increases accordingly. This affects how they use water and where they acquire their water. Plus, the goal is to get young trees off to a good start by not over- or underirrigating. 
The relationship between rate of shoot growth in young trees and SWP is similar to that in mature bearing trees. Consequently, the interpretive stress/no-stress guidelines provided for SWP (see tables 1,7 , and 10) are appropriate for both young and mature trees.

When sampling small trees, particularly during the first year, excessive leaf removal may be an issue if trees are not growing well. One solution is to identify three or four side-by-side rows of uniformly growing trees in a representative area. Each row will have three or four trees identified for SWP measurement. Then, using a rotational schedule, measure SWP in a different row each time, returning to the first row after trees have had time to grow additional leaves suitable for measurement. Typically, second-year and older trees should have sufficient canopy such that rotating between rows of sample trees is not necessary or desirable.

\section{Selecting and Bagging Sample Leaves}

Reflective, water-impervious Mylar foil bags are commonly used for bagging leaves (fig. 7). Bags are available from some pressure chamber manufacturers and retail distributors of food storage

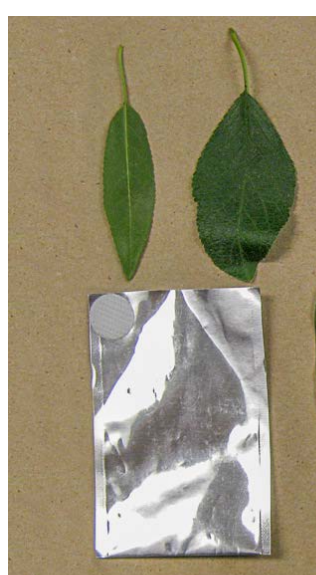

A

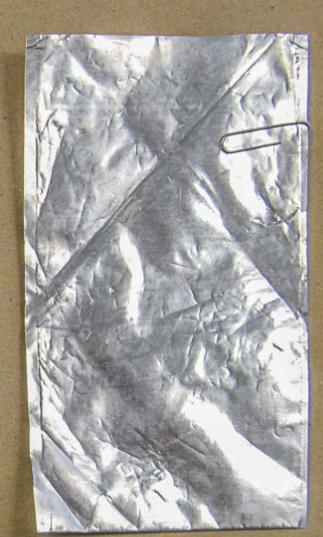

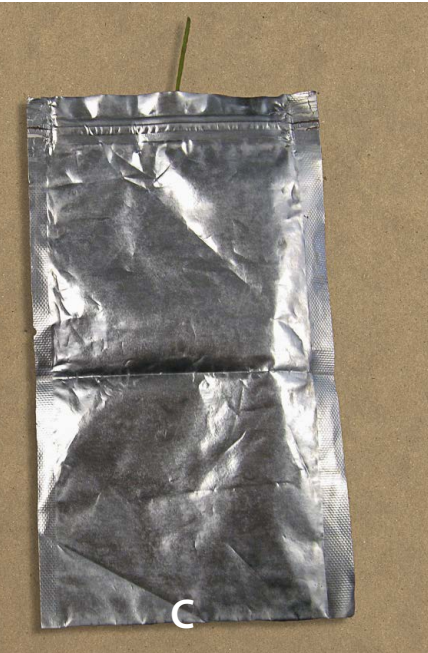

Figure 7. Examples of water-impervious Mylar foil bags. The small bag on the left $(A)$ is used to cover almond and prune leaves, and the larger bags on the right ( $B$ and $C$ ) are used to cover walnut leaves. Photos: A. Fulton. bags, and they are reusable. Bags come in a variety of sizes, and they use various methods of closure and attachment (e.g., ziplock, Velcro, or paper clips). Which method to use is a matter of personal preference and convenience. Bag size is determined by leaf size and the dimensions of the pressure chamber. In general, the smallest bag that will accommodate the sample leaves without damage and that will fit conveniently into the chamber should be selected. It is also possible to make homemade bags using a medium-weight plastic as an interior lining to block water loss and a heavy-duty foil for the exterior to exclude light.
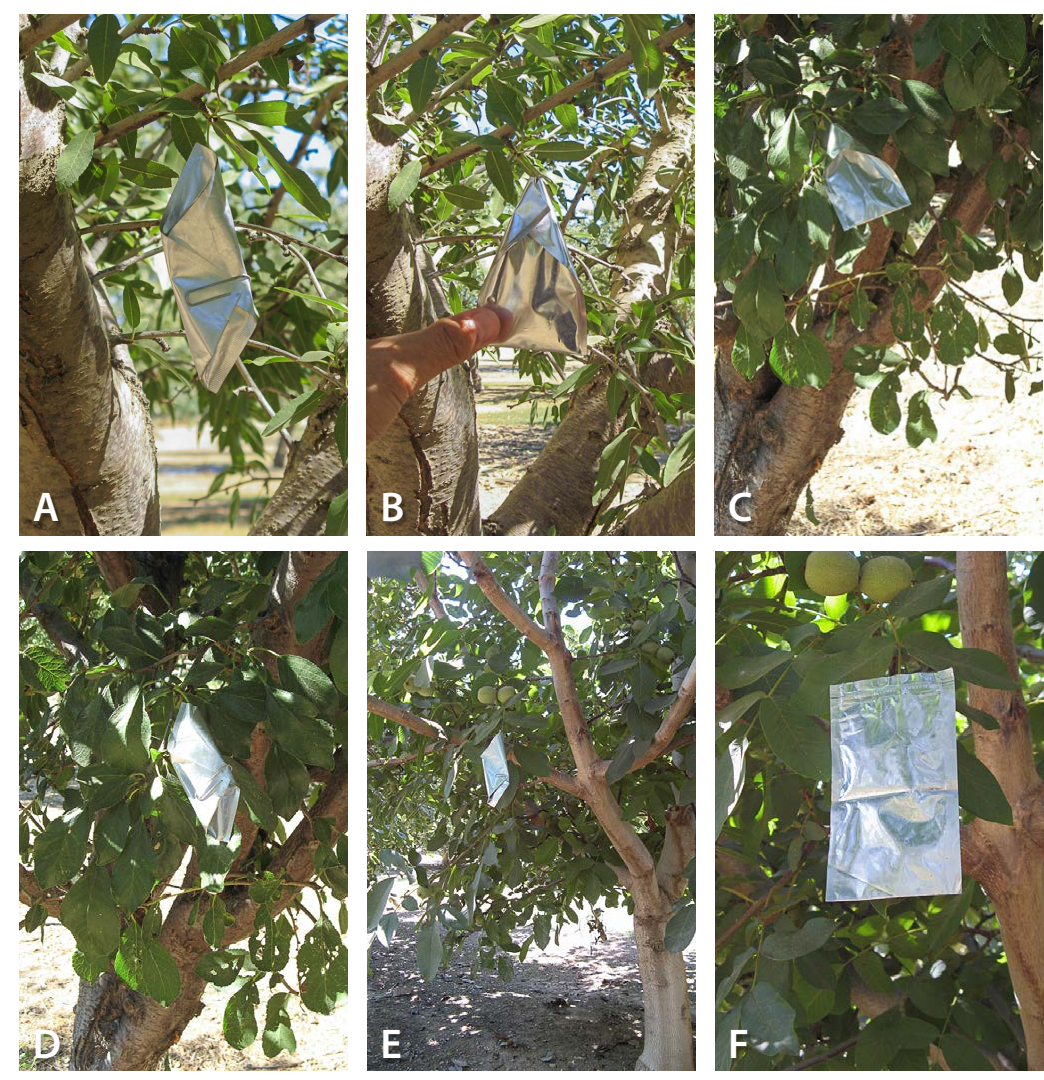

Figure 8. Lower interior leaves are selected on almond (A and B), prune ( $C$ and D), and walnut ( $E$ and $F$ ) to measure SWP. Various methodspaper clip (A), Velcro (B), or ziplock (F)—-may be used to hold bag on leaf. Photos: A. Fulton. 
Bags should be placed on leaves located in the interior shaded canopy of almond, prune, and walnut trees at about shoulder height (fig. 8). Leaves should be healthy, full grown, and without
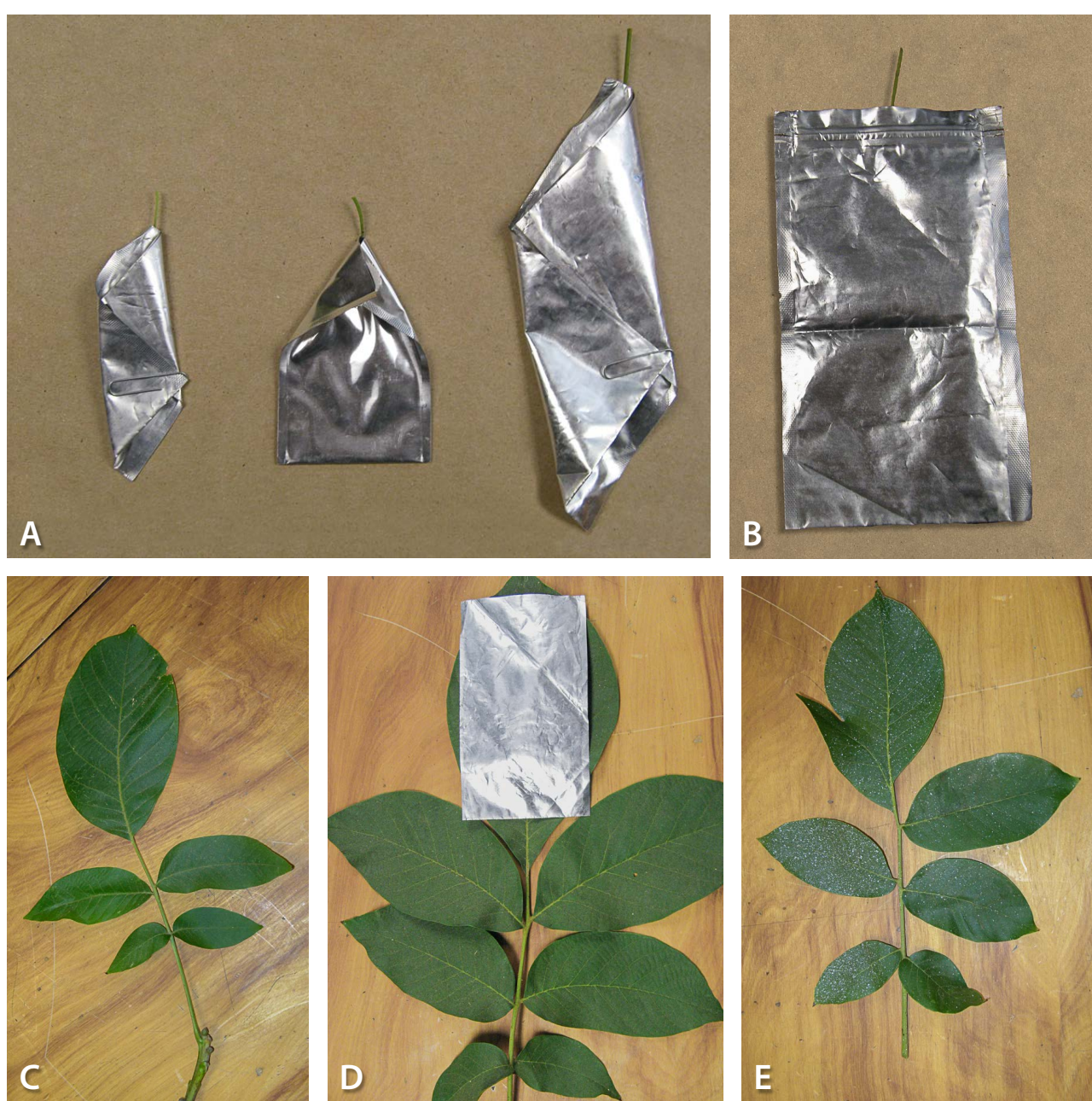

Figure 9. Almond and prune leaves easily fit inside the small Mylar bags with the stem protruding from the top of the bag. Larger Mylar bags are used for walnut (A and B). In walnut, the terminal leaflet with a long stem $(C)$ is selected from the compound leaf. Some terminal leaflets may be too large for the bag or will require gently rolling or folding the leaf to fit into the bag (D). Deformed leaves (E) should be avoided, as their stem is usually too short to extend through the sealing grommet of a pressure chamber. Photos: A. Fulton. apparent nutritional deficiencies, yellowing from excessive shading or older age, or physical damage from wind or hail. Lower interior leaves are selected nearer to larger branches of the tree trunk, where the bagged leaf equilibrates readily with the tree's main water-conducting system. Interior leaves are partially shaded, which expedites leaf equilibration compared with leaves exposed to sunlight and heat. These lower interior leaves are also easier to reach, bag, and excise from the tree compared with leaves higher in the canopy. Consistently using lower, shaded interior leaves for SWP measurements helps reduce variation among readings. One exception might be if trees are sampled very early in the spring after leafing but before the tree canopy is fully expanded. In this case, partially expanded leaves or even shoot tips may be bagged and used to measure SWP.

Generally, smaller almond and prune leaves fit easily into bags, but the larger terminal leaflet on a walnut may be a more difficult fit (fig. 9D). Walnut has a compound leaf with leaflets and a terminal leaflet. The terminal leaflet is the only one with a stem long enough to measure SWP. It is desirable to select terminal leaflets that are small enough to fit inside the bag and do not require folding or rolling. Gently rolling or folding a terminal walnut leaflet and inserting it into the bag is acceptable, but the leaf must not be damaged to the extent that the stem or leaf veins are broken. A pressure chamber operator can suspect broken venation if water bubbles out of the stem prematurely and if measurements are inconsistent. Usually SWP levels within a group of healthy trees with similar canopy size and irrigation will vary at most by -1 or -2 bars. Differences of -5 bars or more typically occur when a sample leaf has been damaged. It is helpful to bag leaves with long stems. Longer stems extend farther out of the top of the pressure chamber and make it easier to observe the endpoint.

\section{Pressure Chamber Operation and Measurement Technique}

Using a consistent technique helps improve the accuracy of SWP measurements. In almonds, as much as a 2-bar discrepancy, plus or minus, has been documented with different operators. Such errors can be due to differences in speed and method of handling 
the sample from the time the leaf is excised until the measurement is completed, or they can be due to differences among operators in recognizing the endpoint (Goldhamer and Fereres 2001).

Relying on one operator to check the same orchards over the
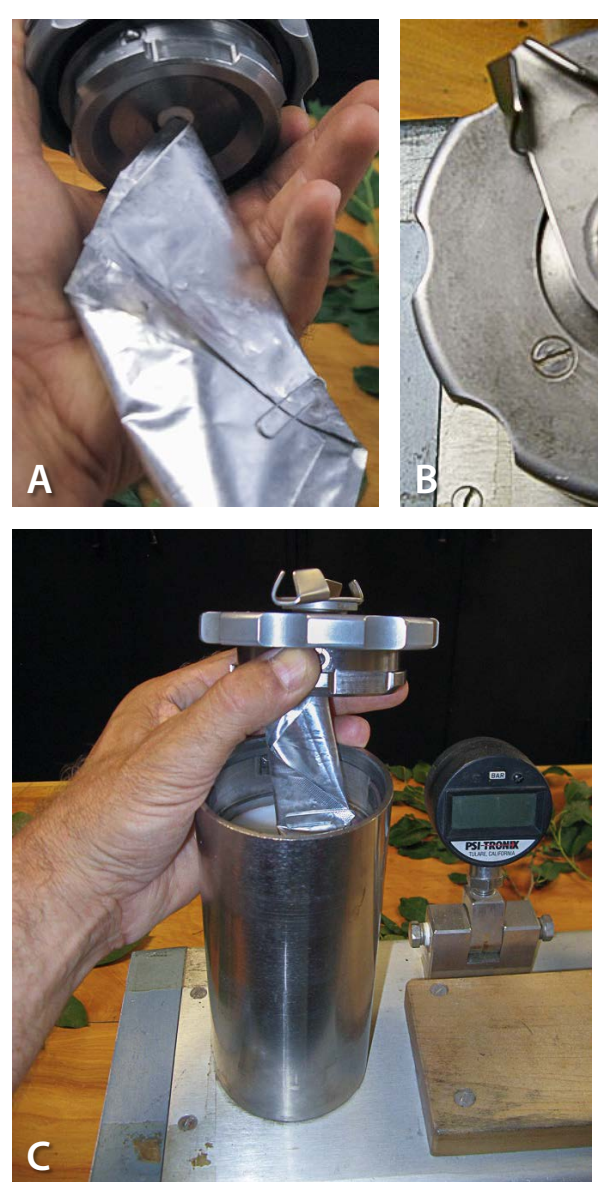

season, using the same pressure chamber and consistent technique, is recommended and will alleviate this problem.

\section{SWP}

measurements of almond, prune, and walnut should be completed as rapidly as possible after bagged leaves are excised. It usually takes an experienced operator 15 to 30 seconds to take a measurement. To minimize variability, readings should be made within 1 minute of being removed from the tree. The endpoint occurs when pressure inside the chamber has equalized

Figure 10. Measuring SWP after the bagged leaf is excised from a tree involves the following: inserting the stem of a bagged leaf upward through the top of the pressure chamber (A); securely tightening the grommet holding the protruding stem of the bagged stem in the pressure chamber cap (B); placing a bagged stem in the pressure chamber after the leaf has been inserted through and securely tightened in the

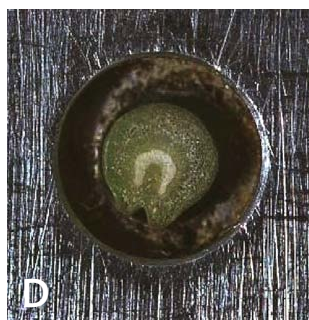
pressure chamber cap (C); and then determining the endpoint for a
SWP measurement (D). Close to the endpoint, water begins to exude from the surface of the cut stem and will appear to glisten. With the addition of a little more pressure, water will cover the entire cross section of the stem and reach the endpoint. At lower SWP levels, the endpoint occurs before bubbling and fizzing are evident. At higher SWP levels, bubbling or fizzing may occur almost instantly as the water covers the surface of the cross section of the stem. Photos: A. Fulton. with water tension in the leaf. The endpoint begins when the surface of the cut stem just begins to glisten at the cut surface (fig. 10D ). Bubbling or fizzing at the cut surface indicates that the endpoint has been exceeded. With almond and prune, particularly at higher levels of crop stress, this may occur almost instantly after water begins to exude from the cut surface. In walnuts, this normally does not occur until the endpoint has been exceeded by a bar or two. If it does occur, the reading should be repeated as described below.

If the endpoint is accidentally exceeded or is in doubt, it can be double-checked by simply reducing the pressure inside the chamber enough so that the water recedes from the surface of the cut stem. Once the water disappears, chamber pressure is again increased and the measurement is retaken to confirm accuracy. This can be done one or two times without taking too much time and compromising an SWP measurement. Good measurement technique also involves carefully bagging and excising bagged leaves to prevent damaging leaf blades or stems. Recutting the end of the stem to have a freshly cut cross section of the stem just prior to inserting it into the top of the pressure chamber may help to see the endpoint. Hold the lid to the pressure chamber upside down in one hand, and then, keeping the leaf inside the bag, with the other hand insert the stem of the bagged leaf into the grommet opening so that the stem sticks out the top side of the pressure chamber lid by about $1 / 4$ to $3 / 4$ inch. Tighten the compression fitting around the stem. To avoid strangling or pinching off the stem, be careful to not overtighten the rubber grommet (fig. 10B). Strangling the stem can be a problem, especially with small almond leaves and stems. If a leaf is torn or the stem is broken, the SWP will not be accurate as previously described because the water-conducting system of the stem will have been compromised. Sometimes pressure chamber operators remove the leaf from the bag to more easily insert the leaf into the pressure chamber. It is preferred to keep the leaf inside the bag when inserting the sample leaf into the pressure chamber. Removing the leaf from the bag before inserting it into the pressure chamber causes the SWP measurement to indicate more stress as the leaf dessicates. The change in SWP due to removing the leaf from the bag may be as little as -0.1 to -0.5 bars if the 
measurement is completed quickly (within 1 minute of excising the leaf from the tree), but the change may be much greater if the measurement is completed more slowly.

Most pressure chambers (excluding handheld pump-up models) incorporate an adjustable metering valve to regulate how fast pressure builds inside the chamber. Metering valves should be set to increase pressure slowly to lessen the chance of missing the endpoint. Experienced operators will set how fast the chamber pressurizes so that it is possible to both watch for the endpoint and read the pressure gauge at the same time. This ability provides a better feel for the measurement and improves confidence and accuracy in observing the endpoint. Experience suggests that a pressure increase of 0.3 to 0.5 bars per second is just about right. In addition, less error occurs when pressure entering the chamber is quickly stopped at the endpoint by using the shut-off valve and not the regulator valve (Naor and Peres 2001). The pressure regulator valve is a needle type that can be easily damaged from overtightening to stop pressure into the chamber.

With a manual or handheld pump-up pressure chamber, the rate of pressurization is easily controlled with the pump. The best
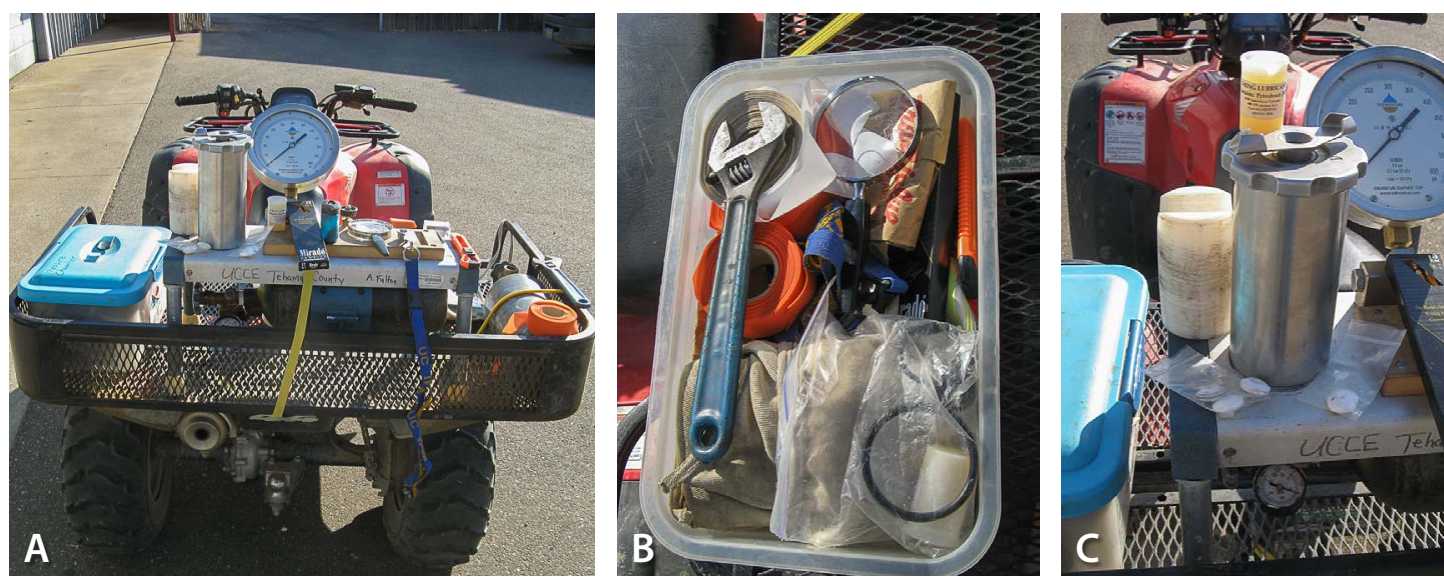

technique with a handheld pressure chamber is to manually pump one or two times, check for the endpoint, and repeat the process until the endpoint is reached. With experience, operators may determine that they can start with 10 or more pumps and then decrease the number as chamber pressure approaches the endpoint.

Pressure leaks while measuring SWP are easily heard and must be corrected. The most common leak occurs at the top of the chamber, where the stem goes through the rubber grommet. Gently tightening the compression on the rubber grommet will stop the leak; however, the operator must not overtighten and strangle the stem. If a leak persists around the grommet, replace the old grommet with a new one. If pressure leaks occur elsewhere, the pressure chamber may require maintenance. For operator safety, discontinue use of a leaky pressure chamber and have it repaired before further use.

\section{Accessories and Suggestions for Measuring SWP Efficiently}

Using a utility or all-terrain vehicle (ATV) is a convenient way to move through an orchard and take SWP measurements. One way

Figure 11. Accessories for measuring SWP efficiently. A pressure chamber is strapped down to a metal rack mounted on the back of an ATV for field measurement of SWP (A). The plastic container to the left of the pressure chamber and in photo (B) holds a number of accessories. Extra rubber grommets, silicon lubricant, and a space saver are useful accessories to maintain and have nearby when using the chamber (C). Razor blades or a utility knife, a magnifying glass, and extra foil bags all kept in a carpenter's apron are useful for bagging and excising leaves as well as observing the endpoint (D). A spare tank of compressed nitrogen, an adjustable wrench, and flagging are useful to avoid running out of nitrogen and to reflag sample trees (C and E). Photos: A. Fulton. 
to set up an ATV for SWP measurements is to attach a rear rack to hold the pressure chamber (fig. 11). Pressure chambers can be topheavy, so strapping the chamber to the rack is a good idea. Remove the pressure chamber from the ATV before loading and unloading the ATV from a pickup or trailer to keep the pressure chamber from tumbling and becoming damaged.

Some accessories are essential to operate a pressure chamber, and others may help to expedite measurements. Foil bags to cover the leaves, a utility knife or a flat razor blade to cut the bagged leaf from the tree, and a minimum $2 \mathrm{X}$ magnifying glass are needed to measure SWP. Magnifying glasses are available with lights to illuminate the cut surface of the stem in the pressure chamber and aid in seeing the endpoint of SWP measurements. An inexpensive carpenter's nail apron will help keep all of these accessories organized and in one place while taking measurements. A small magnet can be glued to the pressure chamber to hold a flat razor blade so it is nearby for cutting sample leaves from trees or making a fresh recut if necessary. An adjustable wrench and a backup bottle of nitrogen gas are essential. If an operator depletes a bottle while in the field, the empty bottle can be replaced and the measurements completed. A space saver that is machined out of plastic or wood and placed into the chamber to fill space not needed for the bagged leaf is useful for reducing the volume of gas needed to pressurize the chamber, effectively saving gas. Using large glass marbles or rubber stoppers inside a plastic bag is another way to reduce chamber volume. Space savers are particularly useful when measuring SWP of smaller almond and prune leaves. This will allow more SWP readings with a single bottle of compressed nitrogen. Before going to the field, lubricate the cam lock on the underside of the top of the chamber. Dust and grime accumulate on the cam lock, making it slow and difficult to turn when taking the chamber top on and off. A small container of silicon lubricant or even a tube of chapstick can be used to lubricate the large O-ring on the underside of the pressure chamber top. Spray lubricants are not suggested, as they may cause rubber gaskets to deteriorate. Pencils, paper, and
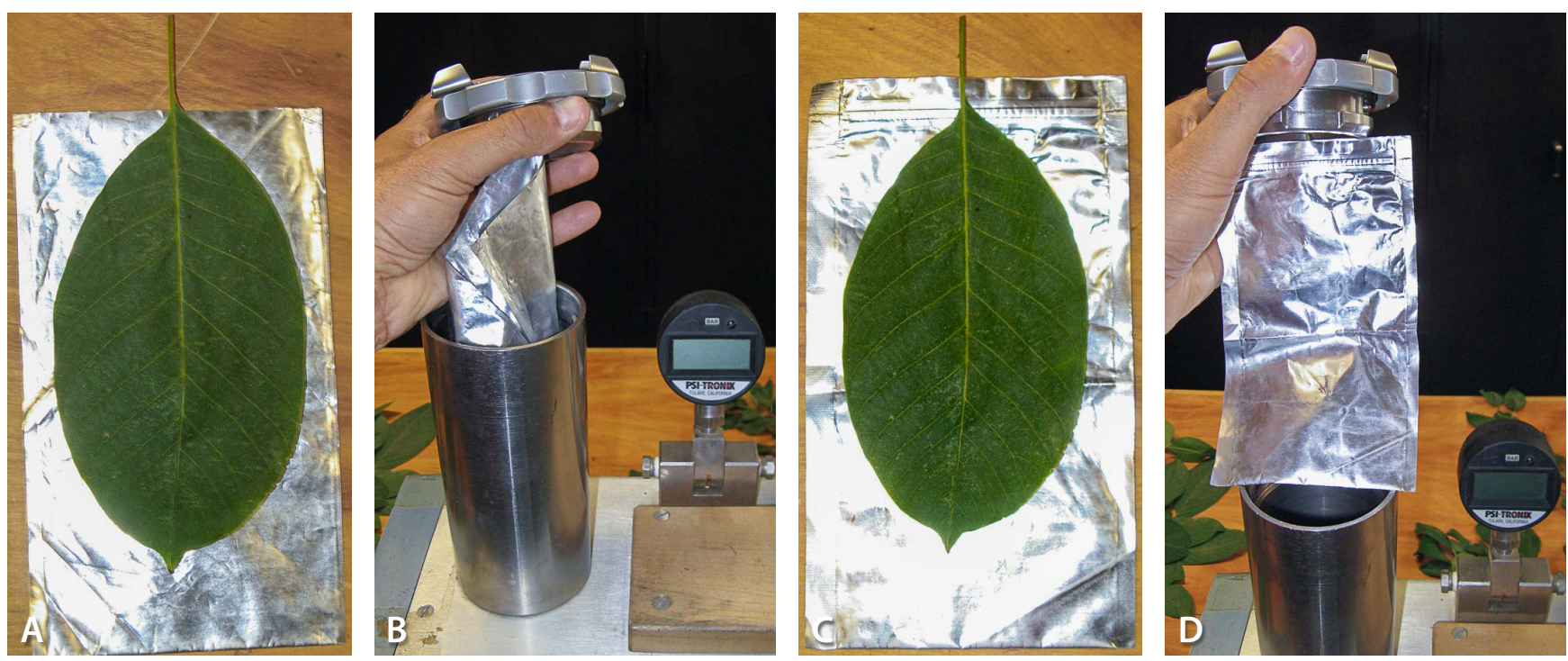

Figure 12. Preparatory steps such as becoming familiar with handling the Mylar bags and practicing SWP measurements in advance of taking field measurements may save time. It may be helpful to trim the ziplock seal and sides of the Mylar bags (A and $C)$, and learn folding methods ( $B$ and $D$ ) so that the sample leaf more readily fits inside the chamber. Photos: A. Fulton. clipboard are needed to record measurements. At the end of the day, it is advisable to store all of these accessories (except the spare tank of nitrogen) in a small container so they do not get lost.

Other preparatory steps may save time as well. As previously mentioned, several fasteners are available for closing bags placed on leaves. Experiment with them and determine whether Velcro adhesive fasteners, small paper clips, or ziplocks are preferred to keep the bag on the sample leaf while it hangs on the tree (see fig. 8). For walnut, which requires larger bags to cover the terminal leaflet, the sides of the bags may be trimmed so that the covered leaf fits more easily into the chamber. Be careful not to trim off too much and damage the bag seam (fig. 12). It may be helpful to practice folding or rolling 
walnut leaves so that they fit more easily into bags-or the bagged leaves into the chamber-without damaging them.

\section{Specific Guidelines for InTERPRETINg SWP Measurements and Scheduling Irrigations in Walnut, Almond, and Prune}

SWP indicates tree water status, making it a reliable irrigation scheduling tool. Tree stress, or orchard water status, is directly related to tree and orchard response, so it is necessary to understand what the measurements mean in terms of orchard performance. This section provides interpretive guidelines for applying SWP

Table 1. Guidelines for interpreting SWP measurements in English walnut

\begin{tabular}{|l|l|l|l|}
\hline $\begin{array}{l}\text { Pressure chamber } \\
\text { reading or SWP } \\
\text { measurement } \\
\text { (bars) }\end{array}$ & $\begin{array}{l}\text { Extent of crop stress and types of crop responses associated with } \\
\text { different SWP levels in English walnut }\end{array}$ \\
\hline 0 to -2.0 & Not commonly observed in English walnut. \\
\hline-2.0 to -4.0 & $\begin{array}{l}\text { Low stress (when fully irrigated). Long-term root and tree health may be a concern, } \\
\text { especially on California black rootstock. }\end{array}$ \\
\hline-4.0 to -6.0 & $\begin{array}{l}\text { Low to mild stress. Promotes shoot growth. Suggested level from leaf-out until } \\
\text { mid-June, when nut sizing is completed. Should maximize rate of shoot growth in } \\
\text { young nonbearing trees. }\end{array}$ \\
\hline-6.0 to -8.0 & $\begin{array}{l}\text { Mild to moderate stress. Shoot growth visible but the rate of growth may } \\
\text { be reduced. These levels do not appear to affect kernel development or bud } \\
\text { fruitfulness for next season. May use to control tree vigor, if desired. }\end{array}$ \\
\hline-8.0 to -10.0 & $\begin{array}{l}\text { Moderate to high stress. Shoot growth in nonbearing trees may stop, nut sizing } \\
\text { may be reduced in bearing trees, and bud fruitfulness for next season may be } \\
\text { reduced. When allowed in young trees in September and early October, slows shoot } \\
\text { growth and promotes green shoots to form woody tissue and prepare for winter. }\end{array}$ \\
\hline-10.0 to -12.0 & $\begin{array}{l}\text { High stress. Temporary wilting of leaves and hull shrivel has been observed. New } \\
\text { shoot growth may be sparse or absent, and some defoliation may be evident. } \\
\text { Edible yield likely to be reduced and kernel color darkened. }\end{array}$ \\
\hline-12.0 to -14.0 & \begin{tabular}{l} 
High levels of stress. Results in a moderate to severe defoliation. Should be avoided. \\
\hline-14.0 to -18.0
\end{tabular} & $\begin{array}{l}\text { Very high stress. Results in severe defoliation. Trees are likely to die. } \\
\text { Crop stress in English walnuts has not been assessed at these levels. Trees usually } \\
\text { die first. }\end{array}$ \\
\hline less than -18.0 & &
\end{tabular}

measurements to manage irrigation in walnut, almond, and prune. Research-based information on crop responses to SWP is also discussed as a foundation for these guidelines, and references are included for additional information.

\section{Using SWP in Walnut Irrigation}

Suggested guidelines for interpreting SWP measurements for English walnut (Juglans regia) are given in table 1. There are many cultivars of English walnut, and they all appear to respond the same with respect to SWP. SWP values in walnut range from -2 to -18 bars. The lowest tree stress levels ( -2 to -4 bars SWP) are usually observed in the spring, shortly following leaf-out, when the weather is cool and soil moisture levels are high from winter rains. Vegetative tree growth and production are favored if irrigation is managed to sustain low levels of tree stress. However, orchards irrigated to sustain little or no tree stress over successive seasons are at greater risk of tree loss from root diseases or injury from insufficient root zone aeration. Experience indicates that low levels of tree stress are more likely to occur when mature bearing walnuts are irrigated according to a water budget. Sometimes irrigation scheduling based on real-time evapotranspiration (ET) estimates does not sufficiently compensate for in-season rainfall and soil moisture reserves from winter rainfall. SWP levels ranging from -4 to -8 bars indicate that walnut is generally growing in low to moderate tree stress conditions. If irrigations are managed to maintain the water status of an orchard within this range over the course of the growing season, the orchard should perform favorably and avoid many problems associated with over- or underirrigation. SWP levels ranging from -8 to -12 bars represent moderate to high tree stress. At these levels, shoot growth, nut sizing, kernel fill, and bud fruitfulness are likely to be adversely affected. The magnitude of these effects depends on how often they occur and how long they persist. Brief, infrequent periods (days) of moderate to high tree stress will not have as great an adverse effect as will extended periods (weeks) of moderate to high tree stress. SWP levels ranging from -12 to -18 bars indicate high to very high tree stress and should be avoided. 


\section{Research Basis for Walnut Guidelines}

Walnut tree responses to different levels of SWP were evaluated from 2002 to 2004 in coordinated experiments in Tehama and San Joaquin Counties in California. One experiment was performed in a young, mechanically hedged Chandler walnut orchard approaching full production (81 trees per acre) in Tehama County. The second experiment was conducted in an unpruned, mature Chandler orchard (49 trees per acre) in San Joaquin County. Chandler walnut was grown on both Paradox (J. hindsii x J. regia) and northern California black (J. hindsii) rootstocks in Tehama County, while Chandler walnut was grown only on Paradox rootstock in San Joaquin County. The Tehama County orchard was planted on shallow, terraced soils with lower water-holding capacity, and the San Joaquin County orchard was growing on deep alluvial soils with greater water-holding capacity. Both sites were

Table 2. The effect of SWP on seasonal shoot growth of mechanically hedged shoots in 8th and 9th leaf (2002 and 2003 seasons) Chandler walnuts grown on Paradox rootstock in Tehama County, California

\begin{tabular}{|c|c|}
\hline $\begin{array}{c}\text { Average seasonal SWP } \\
\text { (bars) }\end{array}$ & $\begin{array}{c}\text { Average seasonal } \\
\text { shoot growth } \\
\text { (feet) }\end{array}$ \\
\hline-3.6 & $3.5^{\mathrm{a}}$ \\
\hline-6.2 & $3.3^{\mathrm{a}}$ \\
\hline-7.5 & $2.4^{\mathrm{b}}$ \\
\hline
\end{tabular}

Source: Fulton and Buchner 2006.

Note: Values followed by different letters are significantly different. irrigated with rotator minisprinklers that gave nearly full coverage. The experiment was terminated at the end of the 2004 season in San Joaquin County, while a fourth year of evaluation was conducted in Tehama County during 2005.

Average seasonal shoot growth (table 2) of the mechanically hedged trees at the Tehama County site was not significantly different among trees grown under low stress (seasonal average -3.6 bars SWP) and mild to moderate stress conditions (seasonal average -6.2 bars SWP). Moderate to moderately high stress conditions (seasonal average -7.5 bars SWP) significantly reduced shoot growth. Results from Tehama suggest that the monthly rate of shoot growth of Chandler walnut is likely to be greater when SWP ranges from -3 to -5 bars, intermediate between -5 to -7 bars, and much lower when SWP is less than -9 bars (fig. 13). The monthly rate of shoot growth was not always high under low crop stress in this mechanically hedged orchard, and it appeared dependent on the diameter of the walnut branch that was

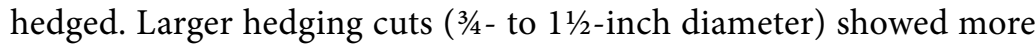
responsive shoot growth than smaller-diameter hedging cuts $(1 / 4-$ to $3 / 4$-inch diameter) even under low levels of crop stress. In a separate experiment, where hand pruning was used to train developing trees, similar relationships between SWP and shoot growth were observed in third and fourth leaf, nonbearing Howard walnuts grown in Tehama County (Fulton 2001). Unlike the Tehama experiment, average seasonal shoot growth was not significantly affected by the levels of tree water stress at the San Joaquin County site. The San Joaquin site consisted of larger unpruned trees and had a more fully developed orchard canopy. The San Joaquin trees had the advantage of deep alluvial soil with greater water-holding capacity. Unpruned trees should have less shoot elongation, particularly with a heavy crop load and with almost all of the shoot growth occurring earlier in the season when deep root zones are full of water and tree water stress is low. The hedged Tehama site had very good shoot elongation, with limited soil moisture storage that was depleted earlier in the season.

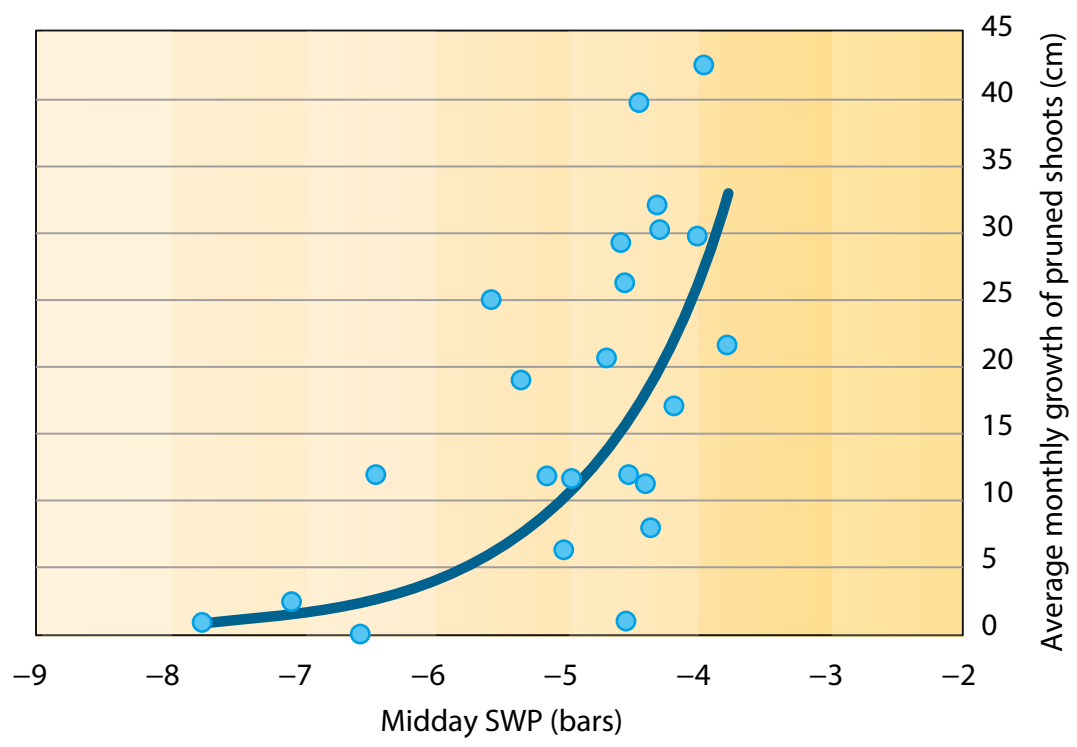

Figure 13. Relationship between stem water potential (SWP) and the average monthly rate of shoot growth of mechanically hedged shoots in Chandler walnuts on Paradox rootstock. Source: Fulton et al. 2002. 
Walnut yield was affected earlier and more significantly in the Tehama County orchard than at the San Joaquin County site (table 3). After 3 consecutive years of imposing different levels of water stress as indicated by SWP, yields declined by 18 to 42 percent

Table 3. Average in-shell yields of Chandler walnuts irrigated to sustain different SWP levels over three seasons (2002-2004) at two locations in the Central Valley of California. Source: Little 2006.

\begin{tabular}{|l|c|c|c|c|c|}
\hline & $\begin{array}{c}\text { 3-year } \\
\text { average SWP } \\
\text { (bars) }\end{array}$ & $\begin{array}{c}\mathbf{2 0 0 2} \text { yield } \\
\text { (T/ac) }\end{array}$ & $\begin{array}{c}\mathbf{2 0 0 3} \text { yield } \\
\text { (T/ac) }\end{array}$ & $\begin{array}{c}\text { 2004 yield } \\
\text { (T/ac) }\end{array}$ & $\begin{array}{c}\text { 2004 yield } \\
\text { reduction (\%) }\end{array}$ \\
\hline & -3.6 & $1.98^{\mathrm{a}}$ & $2.82^{\mathrm{a}}$ & $2.24^{\mathrm{a}}$ & 0 \\
\hline Tehama County* & -6.2 & $1.84^{\mathrm{a}}$ & $2.33^{\mathrm{b}}$ & $1.65^{\mathrm{b}}$ & -26 \\
\hline & -7.5 & $1.74^{\mathrm{a}}$ & $2.07^{\mathrm{b}}$ & $1.31^{\mathrm{b}}$ & -42 \\
\hline San Joaquin & -5.5 & $3.55^{\mathrm{a}}$ & $4.43^{\mathrm{a}}$ & $3.77^{\mathrm{a}}$ & 0 \\
\hline County & -7.0 & $3.26^{\mathrm{a}}$ & $3.94^{\mathrm{a}}$ & $2.98^{\mathrm{b}}$ & -21 \\
\hline & -8.6 & $3.29^{\mathrm{a}}$ & $3.80^{\mathrm{a}}$ & $3.08^{\mathrm{b}}$ & -18 \\
\hline
\end{tabular}

Source: Little 2006.

Notes:

* Tehama County orchard planted in 1995

$\dagger$ San Joaquin County orchard planted in 1986

¥ Values followed by different letters are significantly different.

Table 4. Bud fruitfulness in a 4th year following 3 consecutive years of tree stress in Chandler walnuts grown in California on Paradox rootstock

\begin{tabular}{|l|c|c|c|c|c|}
\hline & $\begin{array}{c}\text { 3-year } \\
\text { average SWP } \\
\text { (bars) }\end{array}$ & $\begin{array}{c}\text { Change in } \\
\text { buds that } \\
\text { opened } \\
\text { Lo) }\end{array}$ & $\begin{array}{c}\text { Change in } \\
\text { floral buds } \\
\text { (\%) }\end{array}$ & $\begin{array}{c}\text { Change in } \\
\text { flowers per } \\
\text { floral bud (\%) }\end{array}$ & $\begin{array}{c}\text { Change in nut } \\
\text { load } \\
\text { (\%) }\end{array}$ \\
\hline & -3.6 & 0 & 0 & 0 & 0 \\
\hline Tehama County* & -6.2 & -1 & -18 & -3 & -24 \\
\hline & -7.5 & -12 & -12 & -9 & -31 \\
\hline $\begin{array}{l}\text { San Joaquin } \\
\text { County }\end{array}$ & -5.5 & & & & \\
\hline
\end{tabular}

Source: Little 2006

Notes:

* Tehama County orchard planted in 1995

† San Joaquin County orchard planted in 1986 in these orchards. At both sites, higher tree stress resulted in fewer dormant buds opening in the spring and fewer floral buds on shoots that did open (table 4). As stress increased, floral buds also had more flowers that set a single walnut and fewer flowers that set double or triple nuts. The same effects resulted in a 16 to 31 percent reduction in fruitfulness in trees grown under an increasing degree of tree stress and helped to explain the yield reductions.

In Tehama County, edible yield of nuts was significantly reduced in 2 of the 4 years under both mild and moderate tree stress levels. Chandler walnuts on northern California black rootstock appeared to be affected more than Chandler walnut on Paradox rootstock (table 5). Edible yield was not significantly reduced under stressed conditions in the San Joaquin County experiment during the 3 years of evaluation. The effect of water stress will depend on the severity, duration, and timing of the stress. Kernel filling and nut quality were not as sensitive to water stress as bud fruitfulness and nut yield.

At the Tehama County site, irrigation management and the associated levels of SWP also had a dramatic and unexpected impact on tree survival (table 6). Tree mortality for Chandler on northern California black rootstock was much higher after 4 years of low-

Table 5. Edible nuts from Chandler walnut trees grown on Paradox hybrid or 'northern California Black' (NCB) rootstock in response to SWP, Tehama County, California, 2002-2005

\begin{tabular}{|l|c|c|c|c|c|}
\hline & 4-year average & \multicolumn{4}{|c|}{ Edible walnuts (\%) } \\
\hline Rootstock & SWP (bars) & $\mathbf{2 0 0 2}$ & $\mathbf{2 0 0 3}$ & $\mathbf{2 0 0 4}$ & $\mathbf{2 0 0 5}$ \\
\hline Paradox & -4.0 & 49.3 & $53.7^{\mathrm{a}}$ & 47.3 & 46.2 \\
\hline Paradox & -6.2 & 49.0 & $51.3^{\mathrm{b}}$ & 48.3 & 46.3 \\
\hline Paradox & -7.2 & 49.8 & $49.4^{\mathrm{c}}$ & 47.8 & 46.3 \\
\hline NCB & -4.0 & 48.4 & $52.5^{\mathrm{a}}$ & 48.8 & $45.4^{\mathrm{a}}$ \\
\hline NCB & -6.2 & 47.8 & $50.7^{\mathrm{b}}$ & 48.5 & $44.2^{\mathrm{b}}$ \\
\hline NCB & -7.2 & 47.9 & $49.6^{\mathrm{c}}$ & 48.8 & $42.8^{\mathrm{c}}$ \\
\hline
\end{tabular}

Source: Buchner et al. 2007.

Note: Values followed by different letters are significantly different. 
Table 6. The effect of 4 years of three different SWP levels on tree health and longevity of Chandler walnuts grown on Paradox and northern California black (NCB) rootstock, Tehama County, California, 2002-2005

\begin{tabular}{|l|c|c|c|c|}
\hline $\begin{array}{l}\text { Walnut } \\
\text { rootstock }\end{array}$ & $\begin{array}{c}\text { Average annual } \\
\text { applied water } \\
\text { (in/ac) }\end{array}$ & $\begin{array}{c}\text { Seasonal average } \\
\text { SWP } \\
\text { (bars) }\end{array}$ & $\begin{array}{c}\text { Trees in mild or } \\
\text { moderate decline } \\
\text { (\%) }\end{array}$ & $\begin{array}{c}\text { Tree death or trees } \\
\text { in severe decline } \\
\text { (\%) }\end{array}$ \\
\hline Paradox & 42 & -4.0 & 0.0 & 0.0 \\
\hline Paradox & 28 & -6.2 & 2.7 & 1.3 \\
\hline Paradox & 23 & -7.2 & 1.3 & 1.3 \\
\hline NCB & 42 & -4.0 & $10.3^{\mathrm{a}}$ & $24.2^{\mathrm{a}}$ \\
\hline NCB & 28 & -6.2 & $6.3^{\mathrm{b}}$ & $3.0^{\mathrm{b}}$ \\
\hline NCB & 23 & -7.2 & $3.1^{\mathrm{b}}$ & $0.0^{\mathrm{b}}$ \\
\hline
\end{tabular}

Note: Values followed by different letters are significantly different. stress irrigation management (averaging -4.0 bars SWP) compared with the other irrigation treatments. There was no tree mortality for Chandler on Paradox rootstock under low-stress irrigation management. Increasing the applied water in order to achieve low orchard stress and higher yields can be fatal to trees, particularly for northern California black rootstock. Higher tree losses occurred when sprinkler water directly hit tree trunks.

In summary, the San Joaquin experiment with older unpruned trees grown on deeper soils with higher water-holding capacity showed less sensitivity of tree growth and production to orchard water stress. The younger, more vigorous mechanically hedged trees on more limiting soil in the Tehama experiment were more sensitive to orchard water stress. Those distinctions may explain different responses between the two sites, emphasizing that every orchard is different.
Table 7. Guidelines for interpreting SWP measurements in almond

\begin{tabular}{|l|l|}
\hline $\begin{array}{l}\text { Pressure chamber reading or } \\
\text { SWP measurement } \\
\text { (bars) }\end{array}$ & $\begin{array}{l}\text { Extent of crop stress and types of crop responses associated with different SWP levels } \\
\text { in almond }\end{array}$ \\
\hline 0 to -6.0 & Not commonly observed in almond. \\
\hline-6.0 to -10.0 & $\begin{array}{l}\text { Low stress (when fully irrigated). Stimulates shoot growth, especially in developing orchards. Higher } \\
\text { yield potential may be possible if these levels of crop stress are sustained over a season, barring no } \\
\text { other limitations related to frost, pollination, diseases, or nutrition. Sustaining these levels may result } \\
\text { in higher incidence of disease and reduced life span. }\end{array}$ \\
\hline-10.0 to -14.0 & $\begin{array}{l}\text { Mild stress. Suitable from mid-June until the onset of hull split (July). Still able to produce } \\
\text { competitively. Recommended crop stress level after harvest. May reduce energy costs or help cope } \\
\text { with drought conditions. }\end{array}$ \\
\hline-14.0 to -18.0 & $\begin{array}{l}\text { Moderate stress. Stops shoot growth in young orchards. Mature almonds can tolerate this level of crop } \\
\text { stress during hull split (July/August) and still yield competitively. May help control diseases such as } \\
\text { hull rot and alternaria, if present. May expedite hull split and lead to more uniform nut maturity. Also } \\
\text { may help reduce energy costs and cope with drought conditions. }\end{array}$ \\
\hline-18.0 to -20.0 & $\begin{array}{l}\text { Moderate to high stress. Should be avoided for extended periods. Likely to reduce yield potential, and } \\
\text { may contribute to lower limb dieback. }\end{array}$ \\
\hline-20.0 to -30.0 & High stress. Wilting observed. Some defoliation. Impacts yield potential. \\
\hline-30.0 to -60.0 & $\begin{array}{l}\text { Very high to severe stress. Extensive or complete defoliation is common. Trees may survive despite } \\
\text { severe defoliation and may be rejuvenated. }\end{array}$ \\
\hline less than -60.0 & Trees are likely to die. \\
\hline
\end{tabular}

\section{Using SWP in Almond Irrigation}

Suggested guidelines for interpreting SWP measurements in almonds are shown in table 7. SWP in almonds has been observed to range from -6 to -60 bars SWP, a much wider range compared with walnuts. Tree and crop responses also progress through the season. Low levels of tree water stress ( -6 to -10 bars SWP) in almonds are usually observed in the spring, shortly after leafing, when the days are shorter, weather is cooler, and rainfall is more abundant. As the season progresses, temperature and day length increase, resulting in SWP levels in the low to mild range $(-10$ to -14 bars SWP) for fully irrigated, mature trees. Excellent yields (over 4,000 pounds per acre) are possible in the southern San Joaquin Valley, when irrigation is managed to maintain tree water status in the low to mild SWP range for the entire season. However, university experiments and production experience supporting intensive irrigation management that sustains almonds at low to mild tree stress 
throughout the season is not conclusive. Almond production regions favoring pollination (i.e., with warmer weather and less rainfall) and receiving more intensive fertility management appear to be more responsive to low tree stress. Concern exists about higher incidence of diseases, lower limb dieback, and shorter orchard life under this management regime. Irrigation managers also need to avoid saturated soils and poor aeration, which compromise root health and tree performance. The decision to adopt intensive irrigation management to sustain low to mild stress involves an economic decision weighing the pros and cons of higher-yielding orchards with potentially shorter life spans versus lesser-yielding (but still competitive) orchards with longer lives.

For locations where frost, pollination, disease, nutrition, or water scarcity result in more variability in cropping, a low tree stress management approach may not be the best management strategy. The use of SWP to impose timely and controlled levels of tree stress in almond may be the better choice. Controlled tree stress is referred to as "regulated deficit irrigation," or RDI. RDI involves withholding water at crop development stages where controlled levels of tree stress do not adversely affect crop yield or kernel quality and might improve tree performance. A possible RDI strategy would include irrigation management that sustains SWP at low to mild levels of stress ( -6 to -14 bars SWP) from leaf out until just prior to hull split. A recent experiment in Glenn County, California (Stewart et al. 2011), where salinity is not a management concern, showed that SWP ranging from -14 to -18 bars (moderate stress) can be tolerated during hull split by almond without economic effects on kernel yield. A return to low to mild stress ( -10 to -14 bars SWP) prior to harvest will help prevent leaf loss during the harvest period. After harvest, sufficient irrigation should be applied to recover tree stress to mild levels ( -10 to -14 bars SWP). In some almondgrowing regions, particularly with later-maturing almond varieties, rainfall may be timely and adequate to supply postharvest water needs.

Hull and foliar diseases are reduced when there is less free moisture and humidity in an orchard (moderate levels of crop stress), and more uniform nut maturity and efficient harvest may be achieved with an RDI approach (Teviotdale et al. 2001; Shackel et al. 2003). Moderate tree stress during hull split has the potential to save water in comparison with a low-stress irrigation strategy, but implementing an RDI strategy does not always result in saving water. Almond orchards not currently monitored with a pressure chamber and SWP may already be under deficit irrigation at higher levels of tree stress than is prudent for RDI. If so, implementing RDI may result in applying more water to correct tree stress prior to the onset of harvest operations (Shackel et al. 2003).

High tree stress ( -20 to -60 bars SWP) will result in increasing levels of defoliation and can reach a point of complete leaf loss. Kernel fill will be reduced, causing more wrinkled nuts and lower kernel weights. As tree stress increases, hull split is affected and a higher incidence of "stick tights" may result, where the nuts remain on the tree following harvest. Severe levels of tree stress will increase the impacts on shoot growth and bud formation, impacting future bloom and tree fruitfulness. Almond has the ability to survive very high to severe tree stress levels, possibly as much as -60 bars SWP. The drawback of severe tree stress is severe reductions in crop yield and quality. In situations where water supply is severely limited, almond may survive severe tree stress for a season, possibly longer, and then recover to nearly full production after sufficient irrigation is restored. Research suggests that the recovery time frame is 2 years or possibly longer (Shackel et al. 2011).

\section{Research Basis for Almond Guidelines}

Table 8 provides almond yield from 2008 through 2010 from a commercial-scale irrigation and fertilizer experiment performed in a mature orchard in Kern County, California. The results illustrate that excellent almond yields (over 4,000 pounds per acre) are achievable when low tree stress, averaging about -10 bars SWP, is sustained throughout the season with intensive irrigation management. Other management practices, such as nitrogen fertilization, as well as weather conditions, must also be optimal.

Table 9 shows yield and kernel size results from a commercialscale irrigation experiment performed from 2004 through 2008 in a young almond orchard in Glenn County, California, that 
Table 8. Almond kernel yields achieved under intensive irrigation (low tree stress) and fertilizer management in Kern County, California

\begin{tabular}{|c|c|c|c|c|c|c|}
\hline $\begin{array}{l}\text { N-K fertilizer } \\
\text { rates (Ib/ac) }\end{array}$ & $\begin{array}{c}2008 \\
\text { average } \\
\text { SWP } \\
\text { (bars) }\end{array}$ & $\begin{array}{l}2008 \text { kernel } \\
\text { yield (lb/ac) }\end{array}$ & $\begin{array}{c}2009 \\
\text { average } \\
\text { SWP } \\
\text { (bars) }\end{array}$ & $\begin{array}{l}2009 \text { kernel } \\
\text { yield (lb/ac) }\end{array}$ & $\begin{array}{c}2010 \\
\text { average } \\
\text { SWP } \\
\text { (-bars) }\end{array}$ & $\begin{array}{l}2010 \text { kernel } \\
\text { yield (lb/ac) }\end{array}$ \\
\hline \multicolumn{7}{|l|}{ Drip irrigation } \\
\hline $125-200$ & NA & NA & $-9.6^{a}$ & 2,722 a & -9.8 & 3,565 \\
\hline $200-200$ & $-9.6^{a}$ & 3,260 a & -9.3 ab & 2,642 a & -9.7 & 3,779 \\
\hline $275-200$ & $-8.5 \mathrm{ab}$ & $3,997 \mathrm{~b}$ & $-8.9 \mathrm{~b}$ & $3,524 \mathrm{~b}$ & -9.7 & 4,266 \\
\hline $275-300$ & $-8.4^{b}$ & $3,839 a b$ & $-8.3^{c}$ & $3,572 b$ & -10.1 & 4,069 \\
\hline $350-200$ & $-9.5 \mathrm{ab}$ & $3,518 \mathrm{ab}$ & -9.7 a & 3,727 b & -9.7 & 4,717 \\
\hline Average & -9.0 & 3,653 & -9.2 & 3,237 & -9.8 & 4,079 \\
\hline LSD 0.05 & 1.1 & 715 & 0.6 & 752 & 0.5 & 457 \\
\hline \multicolumn{7}{|c|}{ Microsprinkler irrigation } \\
\hline $125-200$ & $-10.2 \mathrm{ab}$ & $3,301 \mathrm{ab}$ & $-9.6^{a}$ & $2,722^{a}$ & -9.8 & $3,280^{\text {a }}$ \\
\hline $200-200$ & $-9.7 b$ & $3,360^{b}$ & -9.3 ab & 2,642 a & -9.7 & 3,591 ab \\
\hline $275-200$ & $-10.1 \mathrm{ab}$ & $3,338 \mathrm{ab}$ & $-8.9 \mathrm{~b}$ & $3,524 \mathrm{~b}$ & -9.7 & $3,914 \mathrm{bc}$ \\
\hline $275-300$ & $-10.3^{a}$ & 3,370 a & $-8.3^{c}$ & $3,572 \mathrm{~b}$ & -10.1 & $3,804 \mathrm{bc}$ \\
\hline $350-200$ & $-10.0 \mathrm{ab}$ & $3,963 \mathrm{ab}$ & $-9.7 \mathrm{a}$ & $3,727^{b}$ & -9.7 & $4,165^{c}$ \\
\hline Average & -10.0 & 3,467 & -9.2 & 3,237 & -9.8 & 3,751 \\
\hline LSD 0.05 & 0.6 & 517 & 0.7 & 752 & 0.5 & 415 \\
\hline
\end{tabular}

Source: Brown et al. 2011 .

Note: Values followed by different letters are significantly different.

Table 9. Comparison of 5-year average almond yields where regulated deficit irrigation (RDI) at hull split was practiced and where it was not employed

\begin{tabular}{|l|c|c|c|c|c|c|}
\hline $\begin{array}{l}\text { Irrigation } \\
\text { strategy }\end{array}$ & $\begin{array}{c}\text { Average } \\
\text { kernel yield } \\
\text { (lb/ac) }\end{array}$ & $\begin{array}{c}\text { Standard } \\
\text { error of six } \\
\text { reps (lb/ac) }\end{array}$ & $\begin{array}{c}\text { Average } \\
\text { kernel } \\
\text { weight (g/ } \\
\text { kernel) }\end{array}$ & $\begin{array}{c}\text { Standard } \\
\text { error of six } \\
\text { reps (g/ } \\
\text { kernel) }\end{array}$ & $\begin{array}{c}\text { Severe } \\
\text { kernel } \\
\text { shrivel (\%) }\end{array}$ & $\begin{array}{c}\text { Standard } \\
\text { error of six } \\
\text { reps (\%) }\end{array}$ \\
\hline no RDI & 2,640 & 920 & 1.21 a & 0.12 & 9.0 a & 9.3 \\
\hline $\begin{array}{l}\text { RDI during hull } \\
\text { split }\end{array}$ & 2,640 & 1,090 & $1.18 \mathrm{~b}$ & 0.12 & $13.0 \mathrm{~b}$ & 5.3 \\
\hline
\end{tabular}

Source: Stewart et al. 2011

Note: Values followed by different letters are significantly different. was approaching full production potential. Intensive irrigation management was compared with an RDI strategy. Figure 14 shows that SWP levels in more intensively irrigated almonds were sustained at low to mild levels of tree stress ( -6 to -12 bars SWP) for the entire season. Mild to moderate tree stress ( -12 to -14 bars SWP) was unavoidable for 2 weeks during harvest due to the soil's low water-holding capacity and interruption of irrigation in order to shake, dry, and pick up the nuts. Almond under RDI sustained low to mild tree stress ( -6 to -12 bars SWP) up to the onset of hull split in midsummer. Then irrigation was reduced to impose moderate levels of tree stress ( -14 to -18 bars SWP) for about 3 weeks in addition to moderate tree stress during harvest. Postharvest irrigations were applied in both the intensive and RDI strategies to reduce the tree stress to low or mild levels ( -6 to -12 bars SWP). Almond yields steadily increased throughout the 5 years of the experiment and averaged 2,640 pounds per acre under both the intensive and RDI irrigation management. Under RDI, kernel weight was slightly less and kernel shrivel was slightly higher, while irrigation water was reduced between 10 and 15 percent each season. Previous experiments with RDI in California showed similar results

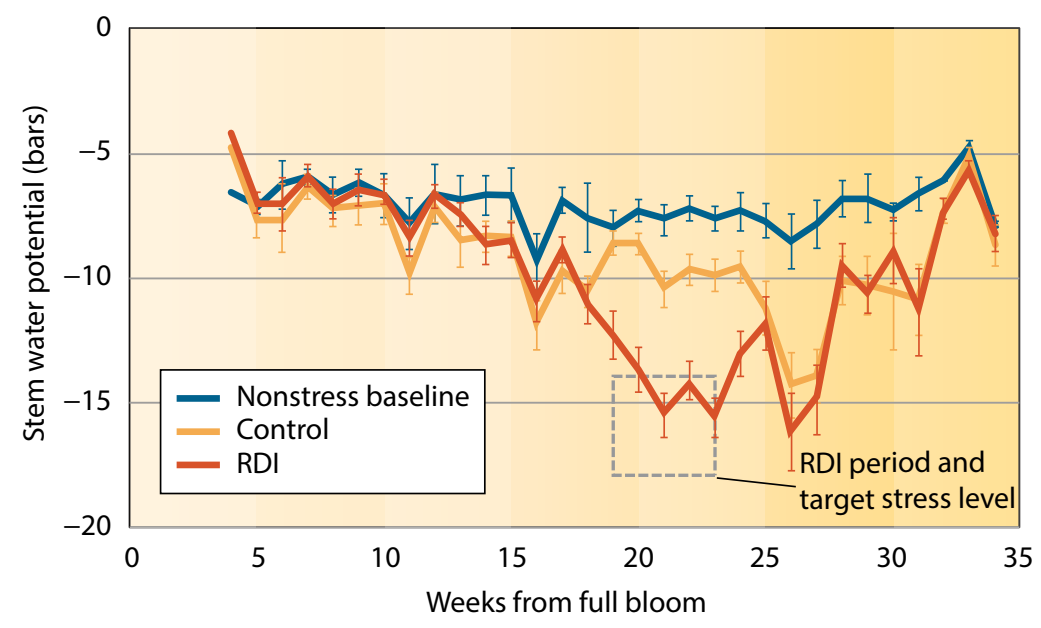

Figure 14. Five-year average seasonal SWP patterns in almonds that were deficit irrigated and those that were not deficit irrigated during hull split. RDI refers to regulated deficit irrigation. Source: Stewart et al. 2011. 
Table 10. Guidelines for interpreting SWP measurements in prune

\begin{tabular}{|c|c|}
\hline $\begin{array}{l}\text { Pressure chamber } \\
\text { reading or SWP } \\
\text { measurement } \\
\text { (bars) }\end{array}$ & $\begin{array}{l}\text { Extent of crop stress and types of crop responses associated with different SWP } \\
\text { levels in prune }\end{array}$ \\
\hline 0 to -6.0 & Not commonly observed in prune. \\
\hline-6.0 to -8.0 & $\begin{array}{l}\text { Very low stress levels. May occur in March and April. Indicates soil moisture is not } \\
\text { limiting. If low crop stress is sustained through the growing season, higher incidence } \\
\text { of disease and tree loss may occur. }\end{array}$ \\
\hline-8.0 to -12.0 & $\begin{array}{l}\text { Low to mild stress. Favors rapid shoot growth and fruit sizing in orchards when low to } \\
\text { mild crop stress is sustained from April through mid-June. }\end{array}$ \\
\hline-12.0 to -16.0 & $\begin{array}{l}\text { Mild to moderate levels of stress. Appropriate beginning in late June through early } \\
\text { August. Rate of shoot growth may be slower but rate of fruit sizing is unaffected. May } \\
\text { help manage energy and irrigation costs. }\end{array}$ \\
\hline-16.0 to -20.0 & $\begin{array}{l}\text { Moderate to high crop stress. Rate of shoot growth slows or stops. Should be avoided } \\
\text { until fruit sizing is completed in early to mid-August. Once fruit sizing is completed, } \\
\text { imposing moderate to high levels of crop stress by reducing irrigation about two } \\
\text { weeks before harvest may increase sugar content in fruit and reduce moisture } \\
\text { content or "dry-away" (drying costs). }\end{array}$ \\
\hline-20.0 to -30.0 & $\begin{array}{l}\text { High to severe crop stress. More likely to occur in late August and early September, } \\
\text { when irrigation is suspended for harvest. Extended periods of high to severe crop } \\
\text { stress before harvest results in defoliation and exposure of limbs and fruit to sunburn. } \\
\text { May also negatively affect the condition of trees going into dormancy. }\end{array}$ \\
\hline less than -30.0 & Severe crop stress. Extended periods of severe crop stress should be avoided. \\
\hline
\end{tabular}

Table 11. Three-year average prune response to three different levels of SWP from June through October

\begin{tabular}{|c|c|c|c|c|c|c|c|}
\hline $\begin{array}{l}\text { Range in } \\
\text { SWP (bars) }\end{array}$ & $\begin{array}{l}\text { Crop stress } \\
\text { level }\end{array}$ & $\begin{array}{c}\text { No. of fruit at } \\
\text { harvest/ac } \\
(\times 1,000)\end{array}$ & $\begin{array}{l}\text { No. of fruit } \\
\text { dropped/ac } \\
(\times 1,000)\end{array}$ & $\begin{array}{c}\text { Dry fruit } \\
\text { yield } \\
\text { (T/ac) }\end{array}$ & $\begin{array}{l}\text { Dry fruit } \\
\text { count } \\
\text { (count/lb) }\end{array}$ & $\begin{array}{c}\text { Fruit drying } \\
\text { ratio }\end{array}$ & $\begin{array}{l}\text { Growth in } \\
\text { trunk cross- } \\
\text { sectional } \\
\text { area } \\
\left(\mathrm{cm}^{2}\right)\end{array}$ \\
\hline-10 to -12 & mild & 5020 & 700 & 6.07 & 61 & 2.99 & 10.53 \\
\hline-12 to -15 & $\begin{array}{l}\text { mild to } \\
\text { moderate }\end{array}$ & 5090 & 560 & 6.03 & 62 & 2.90 & 9.68 \\
\hline-14 to -20 & $\begin{array}{l}\text { moderate to } \\
\text { high }\end{array}$ & 4940 & 490 & 5.73 & 68 & 2.83 & 8.86 \\
\hline LSD (5\%) & & 680 & 100 & 0.54 & 3 & 0.07 & 1.30 \\
\hline
\end{tabular}

Source: Shackel et al. 2000. when RDI was employed (Prichard et al. 1994 and 1996; Goldhamer et al. 2006).

\section{Applying SWP in Prunes}

Interpretive guidelines for SWP in prunes are provided in table 10. Prune can tolerate and possibly benefit from some tree stress if it is controlled and properly timed (Goldhamer et al. 1994). SWP has been observed to range from -6 to at least -30 bars in prunes. SWP stress guidelines are similar for prune and almond as they both belong to the Prunus genera. SWP of -6 to -12 bars represents very low to mild tree stress levels for prune. Irrigation management that sustains SWP between -8 to -12 bars should promote relatively rapid shoot growth in April, May, and June and guard against overirrigation. Mild to moderate stress ranging from -12 to -16 bars SWP may be appropriate beginning in late June through early to mid-August. The rate of shoot growth may decrease, but rate of fruit sizing should be unaffected. Moderate to high tree stress ( -16 to -20 bars SWP) may be tolerated in the week or two before harvest to increase fruit sugar content and improve the dry ratio. To be sure that a moderate to high tree stress is appropriate prior to harvest, fruit pressure and sugar should be monitored in this time frame to ensure that the fruit are not softening too rapidly. After harvest, irrigation should be resumed to reduce the tree stress to mild or moderate levels ( -12 to -16 bars SWP). This will help retain the orchard canopy and store carbohydrate reserves, which should optimize tree health before the trees enter dormancy.

\section{Research Basis for Prune Guidelines}

Table 11 summarizes prune responses to tree stress in an 18-year-old commercial orchard near Gridley, California (Shackel et al. 2000). The soil was a Gridley clay loam and the trees were planted on an 18-by-18-foot spacing on Marianna 2624 rootstock. Irrigation was managed to evaluate three levels of tree stress on orchard performance: 1) mild stress, where SWP was sustained from -10 to -12 bars beginning 
in June and ending in September; 2) mild to moderate stress, where SWP changed from -12 to -15 bars from June through September; and 3) moderate to high stress, where SWP increased from -14

Table 12. Fruit harvest characteristics of prunes at four different levels of fruit thinning when tree stress was maintained between mild to moderate levels (SWP -12 to -18 bars) from June until harvest ${ }^{*}$

\begin{tabular}{|l|c|c|c|c|c|c|}
\hline $\begin{array}{l}\text { Shake } \\
\text { time } \\
\text { (sec) }\end{array}$ & $\begin{array}{c}\text { Number of } \\
\text { prunes per tree }\end{array}$ & $\begin{array}{c}\text { Fruit dry } \\
\text { ratio }\end{array}$ & $\begin{array}{c}\text { Percent of } \\
\text { prunes passing } \\
\text { an “'A" screen }\end{array}$ & $\begin{array}{c}\text { Dry prunes } \\
\text { (count per lb) }\end{array}$ & $\begin{array}{c}\text { Sugar } \\
\text { content } \\
\text { ('Brix) }\end{array}$ & $\begin{array}{c}\text { Fruit } \\
\text { pressure } \\
\text { (psi) }\end{array}$ \\
\hline 1.75 & 1,936 & 2.89 & 70 & 47.2 & 24.8 & 4.7 \\
\hline 1.25 & 2,340 & 3.06 & 56 & 54.9 & 24.2 & 4.4 \\
\hline 0.75 & 3,852 & 3.06 & 51 & 55.5 & 24.3 & 4.5 \\
\hline none & 3,442 & 3.34 & 23 & 72.9 & 20.6 & 4.2 \\
\hline
\end{tabular}

Source: Fulton et al. 2011.

Note: ${ }^{\star S h o w n ~ i n ~ f i g u r e ~} 15$.

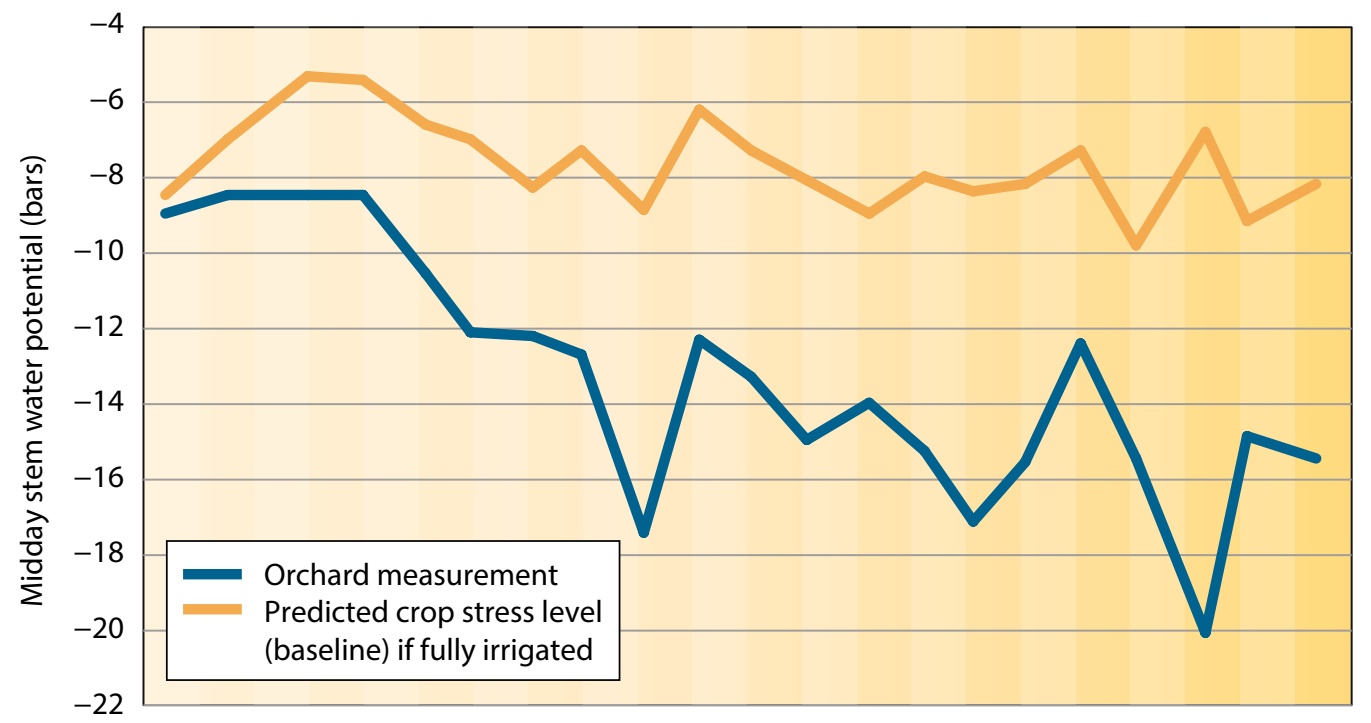

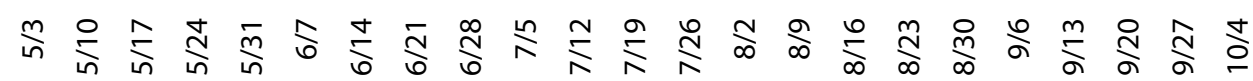

Date

Figure 15. Midday SWP levels observed in a prune orchard that has historically averaged about 4.0 dry tons per acre and consistently achieved desirable fruit size and drying ratio. Source: Fulton et al. 2011. to -20 bars from June through September. Over the 3 years of the experiment, there was no indication that mild to moderate tree stress ( -12 to -15 bars SWP) had any long-term, detrimental effect on prune production. Less fruit drop and significantly lower fruit dry ratios were observed under mild to moderate tree stress, and both responses are considered economically beneficial. Irrigation management that resulted in moderate to high tree stress $(-14$ to -20 bars SWP) also had no effect on dry fruit yield, and it improved fruit dry ratio. However, prune count per pound was significantly higher and growth in trunk cross-sectional area was significantly lower.

Table 12 shows fruit sizing responses of prune in a commercial orchard historically averaging 4.0 dry tons per acre (T/ac). Fruit was thinned to four different crop loads in late May and then irrigated to progressively impose mild to moderate tree stress $(-12$ to -18 bars SWP) from June through August (Fulton et al. 2011). Figure 15 shows the SWP levels that occurred in this orchard during the 2011 season. The results in table 12 emphasize that fruit thinning and crop load influence the fruit dry ratio, the percentage of large prunes, and the sugar content more so than irrigation management and tree stress. When the crop load is appropriate, prunes will achieve the desired size, sugar content, and dry ratio under irrigation management that imposes mild to moderate tree stress. The data illustrates that irrigation management that sustains mild to moderate tree stress from June through August was not able to compensate for trees that were overcropped.

\section{Using Baseline Predictions to Interpret OrchaRd SWP VaLUES}

Because SWP is affected by weather conditions at the time measurements are made, readings can vary from one day to the next as the weather changes, even if irrigation management and soil moisture are relatively stable. The effect on SWP is particularly evident on cloudy days due to reduced sunlight, temperature, and transpiration. SWP measurements should not generally be made under these conditions because measurements are not representative 
of a maximum ET condition and are likely to change after the cloudy conditions pass. For California orchards, weather conditions during the growing season are mostly sunny with fairly constant weather, which tends to make SWP measurements more stable and refinements less necessary. Researchers have developed a refinement of the SWP method-called the baseline concept-for irrigation

Table 13. Baseline SWP (bars) to expect for fully irrigated walnut trees under different conditions of air temperature and relative humidity

\begin{tabular}{|l|l|l|l|l|l|l|l|}
\hline & \multicolumn{7}{|c|}{ Air relative humidity $(\mathbf{R H}, \mathbf{\%})$} \\
\hline Temperature $\left({ }^{\circ} \mathbf{F}\right)$ & $\mathbf{1 0}$ & $\mathbf{2 0}$ & $\mathbf{3 0}$ & $\mathbf{4 0}$ & $\mathbf{5 0}$ & $\mathbf{6 0}$ & $\mathbf{7 0}$ \\
\hline 75 & -4.5 & -4.3 & -4.2 & -4.0 & -3.8 & -3.6 & -3.4 \\
\hline 80 & -4.8 & -4.6 & -4.3 & -4.1 & -3.9 & -3.7 & -3.5 \\
\hline 85 & -5.2 & -5.0 & -4.7 & -4.4 & -4.1 & -3.9 & -3.6 \\
\hline 90 & -5.6 & -5.2 & -4.9 & -4.6 & -4.3 & -4.0 & -3.7 \\
\hline 95 & -6.0 & -5.7 & -5.3 & -5.0 & -4.6 & -4.3 & -3.9 \\
\hline 100 & -6.5 & -6.1 & -5.7 & -5.3 & -4.9 & -4.5 & -4.0 \\
\hline 105 & -7.2 & -6.7 & -6.2 & -5.7 & -5.2 & -4.8 & -4.3 \\
\hline 110 & -7.8 & -7.3 & -6.7 & -6.2 & -5.6 & -5.0 & -4.5 \\
\hline 115 & -8.7 & -8.0 & -7.4 & -6.7 & -6.0 & -5.4 & -4.8 \\
\hline
\end{tabular}

Table 14. Baseline SWP (bars) to expect for fully irrigated almond or prune trees under different conditions of air temperature and relative humidity

\begin{tabular}{|l|c|c|c|c|c|c|c|}
\hline & \multicolumn{7}{|c|}{ Air relative humidity (RH, \%) } \\
\hline Temperature (') & $\mathbf{1 0}$ & $\mathbf{2 0}$ & $\mathbf{3 0}$ & $\mathbf{4 0}$ & $\mathbf{5 0}$ & $\mathbf{6 0}$ & $\mathbf{7 0}$ \\
\hline 75 & -7.3 & -7.0 & -6.6 & -6.2 & -5.9 & -5.5 & -5.2 \\
\hline 80 & -7.9 & -7.5 & -7.0 & -6.6 & -6.2 & -5.8 & -5.4 \\
\hline 85 & -8.5 & -8.1 & -7.6 & -7.1 & -6.6 & -6.1 & -5.6 \\
\hline 90 & -9.3 & -8.7 & -8.2 & -7.6 & -7.0 & -6.4 & -5.8 \\
\hline 95 & -10.2 & -9.5 & -8.8 & -8.2 & -7.5 & -6.8 & -6.1 \\
\hline 100 & -11.2 & -10.4 & -9.6 & -8.8 & -8.0 & -7.2 & -6.5 \\
\hline 105 & -12.3 & -11.4 & -10.5 & -9.6 & -8.7 & -7.8 & -6.8 \\
\hline 110 & -13.6 & -12.6 & -11.5 & -10.4 & -9.4 & -8.3 & -7.3 \\
\hline 115 & -15.1 & -13.9 & -12.6 & -11.4 & -10.2 & -9.0 & -7.8 \\
\hline
\end{tabular}

managers who want to account for this effect. The baseline SWP for any given day and time is defined as the SWP that is expected if soil moisture is abundant and not limiting transpiration under the prevailing temperature and humidity conditions.

Baseline values are derived from mathematical models and have been validated in field experiments on walnut, almond, and prune. (McCutchan and Shackel 1992). Estimates of baseline SWP for walnut, almond, and prune over a range of air temperatures and relative humidity are provided in tables 13 and 14. An online calculator of baseline SWP is also available at the Fruit and Nut Research and Information Center website, http://informatics. plantsciences.ucdavis.edu/Brooke_Jacobs/index.php. Baseline SWP values provide additional perspective when interpreting SWP readings for irrigation scheduling. However, including the baseline SWP in the interpretation is not essential, especially if the added level of complexity deters use of the pressure chamber and SWP as an irrigation scheduling tool. Estimating the baseline will require access to public or private weather databases (e.g., CIMIS), which provide hourly temperature and relative humidity data, or a simple handheld instrument that can measure temperature and relative humidity in the orchard at the same time that SWP measurements are taken.

The baseline SWP values for walnut, almond, and prune will change with weather conditions (see tables 13 and 14). Remember, ranges in SWP potential are different in walnut compared with almond and prune. Some example applications of baseline SWP are described for walnut, and similar uses can be applied to almond and prune. During cool weather, estimates of baseline SWP may be -3 to -4 bars in walnut. However, under hot and dry weather conditions, baseline SWP for walnut may be -6 to -7 bars. An example of overirrigation would be if the walnut baseline is -3 to -4 bars SWP and pressure chamber measurements are consistently within the range of -2 to -4 bars SWP. In this scenario, trees may be overirrigated and root zones too wet. An example of when the use of baseline SWP helps distinguish tree water stress would be a day when the walnut baseline is -5 bars SWP and the orchard SWP measurements are -8 bars SWP. This would clearly suggest 
that tree water stress is occurring and that the need for irrigation is approaching. On a very hot, windy day, when the baseline is -7 bars SWP and the orchard measurement is -8 bars SWP, it would suggest that tree stress is occurring. However, these readings are more associated with the hot, dry weather conditions than with irrigation management. Under such conditions, mild tree stress can occur even when irrigation management is on track and soil moisture is not limiting. Once the hot, dry weather passes, both the estimate of baseline SWP and the orchard SWP measurements will recover to levels indicating lower tree stress.

\section{How Is SWP Influenced by Other Orchard VARIABLES?}

Other tree and orchard features, besides irrigation, can impact plant water relations and SWP. Understanding how these factors can influence SWP can help interpret SWP readings to improve irrigation management decisions.

\section{Too Much or Too Little Water}

Is it possible to mistake overirrigation for underirrigation when monitoring orchard water status using SWP? No. Overirrigation is distinguishable from underirrigation with SWP measurements. The water status of an orchard that is irrigated too frequently or receiving excess water each irrigation will consistently have SWP levels indicating low tree stress before and after irrigation. Orchard SWP measurements will mimic baseline estimates of SWP. As a consequence, tree root systems will be at greater risk of damage from extended periods of poor root zone aeration and damage from crown and root diseases. An orchard that is overirrigated will not begin to express high or severe levels of tree stress until the root system has been damaged enough such that the uptake of water into the tree is compromised. In contrast, an orchard that is deficit irrigated will show extended periods of time when SWP reflects orchard water status at moderate, high, or severe levels of tree stress. A large separation ( 4 bars or more) will be apparent between baseline estimates of SWP and the orchard levels. An orchard that is irrigated optimally with not too much or too little water will show fluctuations in SWP, ranging from low to mild tree stress after irrigation to mild or moderate tree stress prior to irrigation. Typically there will be a 1 to 3 bar difference between the baseline estimate of SWP and the orchard measurements.

\section{Soil and Water Salinity}

Walnut, almond, and prune are moderately sensitive to root zone salinity, expressed as "osmotic potential" in the tree. The ability of water to move from the soil into the root is reduced when salts accumulate in the root zone. The increased osmotic potential due to a salt-affected soil increases the resistance of water flow into the root and this increases the total water potential, which is measured with SWP. Trees adjust to higher soil-water salinity by storing more sugars and organic acids in their roots to overcome this resistance and maintain movement of water from the soil into the root. However, this adjustment occurs at the expense of tree growth and production. SWP reflects both the effect of water availability as influenced by irrigation and the stress-inducing effects of salts. As such, SWP measurements in salt-affected soils can reflect actual tree water stress better than indirect methods of irrigation scheduling such as the water budget method or soil moisture monitoring.

\section{Fruit or Nut Set (Crop Load)}

Evidence in prune suggests crop load may affect SWP. A heavy crop may contribute to greater tree stress. However, the effect is relatively small and not consistent by season even when crop loads are similar. Additional research is necessary to understand the influence of crop load on SWP. Experience suggests that SWP can provide additional information about the effect of yield potential on soil-plant water relations unlike soil moisture monitoring and water budgets.

\section{Soil Fertility and Plant Nutrition}

The influence of soil fertility and plant nutrition on SWP is not well understood and is another area for additional research. It would most likely require severely deficient or excessive levels of soil fertility or plant nutrition (or both) to significantly influence SWP. 


\section{Tree Diseases}

Root diseases such as Phytophthora crown and root rot are favored by water-saturated soil. These diseases damage root and vascular systems so they can no longer meet tree water demand, resulting in higher levels of tree stress compared with healthy trees. Other diseases such as crown gall (Agrobacterium tumefaciens) are not directly associated with water management, but they also damage the water-conducting system. Trees with damaged roots or waterconducting systems will not show much, if any, recovery in tree stress after irrigation and usually decline and eventually die.

Foliar diseases may potentially affect SWP. Shot hole (Wilsonomyces carpophilus) in almond and leaf rust (Tranzschelia discolor) in prune are two examples. If these diseases are not controlled, trees defoliate prematurely, which can reduce transpiration rates depending on the severity of leaf loss. SWP readings may indicate lower tree stress levels than usual and indicate the need to adjust the water management program if leaf loss is severe enough.

\section{Other Pests}

The influence of insects, mites, and nematodes on SWP is not well documented by research. Aphid, spider mite, scale, Lepidoptera insects, and bark borers are not likely to directly affect SWP or tree stress unless they damage foliage or structural wood to the point of causing significant leaf loss and consequently affecting transpiration. However, nematodes and other insect pests that feed on root systems can significantly damage the fine feeder roots critical for water uptake, resulting in increased tree stress.

\section{Rootstocks and Cultivars}

Just as there are many potential site-specific scenarios for diseases and pests, there are many cultural practices that may also influence SWP in some way. One example is the effect of walnut, almond, and prune rootstock and variety on SWP. Current research-based knowledge about the relationships between SWP and modern rootstocks and cultivars is limited. Experience indicates that the suggested SWP guidelines presented in this publication work well for walnut, almond, and prune regardless of rootstock and variety. In walnut, for example, similar SWP levels have been observed for Chandler walnut grown on both hybrid Paradox and northern California black rootstock when they are subjected to the same irrigated conditions. Preliminary data from a rootstock experiment with young Howard walnuts suggests no differences in SWP between newer Vlach, RX1, VX211, and Paradox seedling rootstock. The same has been observed among the commonly planted Lovell peach and Marianna 2624 plum rootstocks for almond and its cultivars. However, no data exists on potential differences that might arise in the newer Hanson, Bright, and Krymsk 86 almond rootstock.

\section{Orchard Canopy Management}

Mechanical hedging or pruning may affect canopy size and light interception. Both of these factors can affect transpiration and crop load, depending on the degree of hedging or pruning. As a result, SWP may be sensitive to changes in orchard canopy management and may result in adjusting irrigation schedules. This is one more benefit of using the pressure chamber and SWP as an irrigation management tool.

\section{SWP: Stand-Alone or Complementary IRRIGATION MANAGEMENT TOOL?}

As a direct measure of tree response to irrigation management and the soil, climate, and orchard environment, SWP is unique compared with other methods that assess tree water status indirectly. As such, through trial and error, SWP can be used-and has been successfully adopted by many growers-as a stand-alone technique for irrigation scheduling in almond, walnut, and prune. Using SWP alone, along with the interpretive guidelines presented in this publication, gives a relatively straightforward answer to the question of when to irrigate.

However, trial and error may not suffice in some situations, and SWP measurements alone may not provide enough information. For example, pressure chamber measurements can show low crop 
stress in April, May, and early June in orchards grown even though irrigation has been postponed or reduced. The trees consume water stored in the root zone from winter rainfall or winter irrigation during this period to satisfy their water requirements. Without some monitoring of soil moisture or tracking of ET, it is possible to experience a sudden and rapid increase in tree water stress in July, August, and September. Meanwhile, a drip or microsprinkler irrigation system will not have the capacity to apply enough water to recharge the soil moisture depletion and sufficiently relieve tree stress. This can be a problem particularly in orchards where soils have slow water infiltration. Irrigation should be initiated before the stored water is depleted excessively. Irrigation set times should be selected to avoid long run times that result in waterlogged soils and increased risk of injury to the root system, while still taking care to replace most of the extracted water.

Using SWP in conjunction with soil moisture monitoring or a water budget (or both) can also help overcome some common limitations of soil moisture monitoring and irrigating according to ET. SWP readings that indicate low tree stress, even though soil moisture sensors indicate dry soil, might suggest that trees are getting water from greater depths in the root zone that are not being monitored by soil moisture sensors. This situation could indicate a need for deeper soil moisture monitoring or placing soil moisture sensors in more representative locations. Similarly, SWP readings that indicate desirable levels of tree stress, even when a water budget indicates underirrigation, suggest the need to reexamine assumptions about ET rates, rooting depth, and available moisture reserves. In a different situation, SWP measurements might indicate moderate to high tree stress even when soil moisture sensors placed within the wetted pattern of the drip emitter show high soil moisture content. In this case, additional investigation is necessary to determine if soil moisture sensors accurately represent the root zone and predominant soil types or if the sensors are defective. It may be possible that roots extend beyond the areas wetted by drip emitters or microspinklers. This situation is more likely to occur where rainfall plays a more prominent role in supplying orchard water needs. If the entire soil profile is recharged with rainfall, roots are not confined to the drip zone and can extract moisture from a much larger area.

\section{References}

Ameglio, T., P. Archer, M. Cohen, C. Valancogne, F. Daudet, and P. Cruiziat. 1999. Signficance and limits in the use of predawn leaf water potential for tree irrigation. Plant Soil 207:155-167.

Bates, L. M., and A. E. Hall. 1981. Stomatal closure with soil water depletion not associated with bulk leaf water potential. Oecologia 50:62-65.

Brown, P., K. Shackel, J. Hopmans, B. Lampinen, B. Sanden, D. Smart, S. Ustin, and M. Whiting. 2011. Almond irrigation, nutrition for high yield and stewardship. Report for Kern County Field Day. University of California Cooperative Extension, Kern County.

Buchner, R. P., A. Fulton, C. Gilles, B. Lampinen, K. Shackel, S. Metcalf, C. Little, T. Pritchard, and L. Schwankl. 2007. Effects of regulated deficit irrigation on walnut (Juglans regia) grafted on northern California black (Juglans hindsii) or Paradox rootstock. Proceedings of the 5th International Symposium on Irrigation of Horticultural Crops. 141-146.

Fruit and Nut Research and Information Center website, http:// informatics.plantsciences.ucdavis.edu/Brooke_Jacobs/index. php.

Fulton, A., and R. Buchner. 2006. The effect of water stress on walnut tree growth, productivity, and economics. UCCE Farm Advisors Draft Publication. University of California Cooperative Extension, Tehama County.

Fulton, A., R. Buchner, C. Gilles, and S. Ferguson. 2011. Irrigating to produce consistent, competitive yields and high quality French prunes. Annual Report. California Prune Board.

Fulton, A., R. Buchner, C. Little, and C. Gilles. 2001. Shoot growth response of third leaf Howard walnuts to midday stem 
water potential. Walnut Research Reports. California Walnut Research Board and Commission.

Fulton, A., R. Buchner, C. Little, C. Gilles, J. Grant, B, Lampinen, K. Shackel, L. Schwankl, T. Prichard, and D. Rivers. 2002. Relationships between midday stem water potential, soil moisture measurement, and walnut shoot growth. Walnut Research Reports. California Walnut Research Board and Commission.

Fulton, A., R. Buchner, B. Olson, L. Schwankl, C. Gilles, N. Bertagna, J. Walton, and K. Shackel. 2001. Rapid equilibration of leaf and stem water potential under field conditions in almonds, walnuts, and prunes. Hortechnology 11(4): 609-615.

Fulton, A., M. Salinas, A. Montoro, and D. Goldhamer. Evaluation of trunk or scaffold shrinkage as an indicator of orchard water status. 2003. Walnut Research Reports. California Walnut Research Board and Commission.

Garnier, E., and A. Berger. 1985. Testing water potential in peach trees as an indicator of water stress. Journal of Horticultural Science 60:(1): 47-56.

Goldhamer, D., A. M. Viveros, and M. Salinas. 2006. Regulated deficit irrigation in almond: Effect of variations in applied water and stress timing on yield and yield components. Irrigation Science 24:101-114.

Goldhamer, D., and E. Fereres. 2001. Simplified tree water status measurements can aid almond irrigation. California Agriculture 55(3): $32-37$.

Goldhamer, D. A., G. S. Sibbett, R. C. Phene, and D. G. Katayama. 1994. Early irrigation cutoff has little effect on French prune production. California Agriculture 48(4): 13-17.

Grimes, D. W., and H. Yamada. 1982. Cotton growth related to plant water status. California Agriculture 36(11): 13-14.

Jones, H. G. 1985. Physiological mechanisms involved with the control of leaf water status: Implications for the estimation of tree water status. Acta Horticulturae 171: 291-296.

Little, C. 2006. The effect of deficit irrigation on yield and vegetative growth in English walnuts. Master's thesis. University of California, Davis.

McCutchan, H., and K. A. Shackel. 1992. SWP as a sensitive indicator of water stress in prune trees (Prunus domestica L.cv French). Journal of the American Society of Horticultural Science 117:607-611.
Naor, A., and M. Peres. 2001. Pressure increase rate affects the accuracy of stem water potential measurements in deciduous trees using the pressure chamber technique. Journal of Horticultural Science and Biotechnology 76(6): 661-663.

Olien, W. C., and A. N. Lakso. 1986. Effect of rootstock on apple (Malus domestica) tree water status. Physiologia Plantarum 67(3): 421-430.

Pearson. 2008. Upper Saddle River, NJ: Pearson Education Inc.

Plant Moisture Stress (PMS) Instrument Company website, http:// pmsinstrument.com/.

Prichard, T., W. Asai, P. Verdegaal, W. Micke, and B. Teviotdale. 1994. Effects of water supply and irrigation strategies on almonds. Comprehensive Project Report, Project No. 93-H5. Modesto: California Almond Board.

Prichard, T., P. Verdegaal, W. Asai, and W. Micke. 1996. Residual effects of water deficits and irrigation strategies on almonds. Project No. 95-M7 Report. Modesto: California Almond Board.

Scholander, P. F., H. T. Hammel, E. D. Bradstreet, and E. A. Hemmingsen. 1965. Sap pressure in vascular plants. Science 148(3668): 339-346.

Shackel, K., R. Buchner, J. Connell, R. Duncan, J. Edstrom, A. Fulton, B. Holtz, B. Lampinen, B. Krueger, W. Reil, M. Viveros, and L. Schwankl. 2003. Deficit irrigation management during hull-split. Annual report. Modesto: California Almond Board.

Shackel, K., J. Edstrom, A. Fulton, B. Lampinen, and L. Schwankl. 2011. Irrigation management of almonds when water supplies are limited. Proceedings of the American Society of Agronomy, California Chapter Conference: 93-98.

Shackel, K. A., B. Lampinen, S. Southwick, W. Olson, S. Sibbett, W. Krueger, and J. Yeager. 2000. Deficit irrigation in prunes: Maintaining productivity with less water. HortScience 35(6): 1063-1066.

Soilmoisture Equipment Corp. website, http://www.soilmoisture.com/.

Specialty Engineering website, http://www.billetballs.com/products.

Stewart, W. C., A. Fulton, W. H. Krueger, B. D. Lampinen, and K. A. Shackel. 2011. Regulated deficit irrigation reduces water use of almonds without affecting almond yield. California Agriculture 65(2): 90-95. 
Teviotdale, B. L., D. A. Goldhamer, and M. Viveros. 2001. Effects of deficit irrigation on hull rot disease of almond trees caused by Monilinia

fructicola and Rhizopus stolonifer. Plant Disease 85(4): 399-403.

Turner, N. C., and M. J. Long. 1980. Errors arising from rapid water loss in the measurements of leaf water potential. Australian Journal of Plant Physiology 7:527-537.

Waring, R. H., and B. D. Cleary. 1967. Plant moisture stress: Evaluation by pressure bomb. Science 155(3767): 1248-1254.

Williams, L. E., and F. J. Araujo. 2002. Correlations among predawn leaf, midday leaf, and midday stem water potential and their correlations with other measures of soil and plant water status in Vitis vinifera. Journal of the American Society of Horticultural Science 127:448-454.

\section{For MORE Information}

To order or obtain ANR publications and other products, visit the ANR Communication Services online catalog at http://anrcatalog.ucanr.edu or phone 1-800-994-8849. You can also place orders by mail or FAX, or request a printed catalog of our products from

\section{University of California}

Agriculture and Natural Resources

Communication Services

1301 S. 46th Street

Building 478 - MC 3580

Richmond, CA 94804-4600

Telephone 1-800-994-8849

510-665-2195

FAX 510-665-3427

E-mail: anrcatalog@ucanr.edu

(C2014 The Regents of the University of California

Division of Agriculture and Natural Resources

All rights reserved.

Publication 8503

ISBN-13: 978-1-60107-858-2

The University of California Division of Agriculture \& Natural Resources (ANR) prohibits discrimination against or harassment of any person participating in any of ANR's programs or activities on the basis of race, color, national origin, religion, sex, gender identity, pregnancy (which includes pregnancy, childbirth, and medical conditions related to pregnancy or childbirth), physical or mental disability, medical condition (cancer-related or genetic characteristics), genetic information (including family medical history), ancestry, marital status, age, sexual orientation, citizenship, or service in the uniformed services (as defined

\section{Measurement Conversion Table}

\begin{tabular}{|l|c|c|l|}
\hline U.S. customary & $\begin{array}{c}\text { Conversion factor } \\
\text { for U.S. customary } \\
\text { to metric }\end{array}$ & $\begin{array}{c}\text { Conversion factor } \\
\text { for metric } \\
\text { to U.S. customary }\end{array}$ & Metric \\
\hline pound per acre (lb/ac) & 1.12 & 0.89 & kilogram per hectare $(\mathrm{kg} / \mathrm{ha})$ \\
\hline ton per acre (T/ac) & 2.24 & 0.446 & metric ton per hectare (t/ha) \\
\hline $\begin{array}{l}\text { pound per square } \\
\text { inch (psi) }\end{array}$ & 0.00689 & 145.0 & megapascal (kPa) \\
\hline bar & 0.1 & 10.0 & megapascal $(\mathrm{mPa})$ \\
\hline centibar & 0.001 & 0.1 & megapascal $(\mathrm{mPa})$ \\
\hline
\end{tabular}

by the Uniformed Services Employment and Reemployment Rights Act of 1994: service in the uniformed services includes membership, application for membership, performance of service, application for service, or obligation for service in the uniformed services) or any person in any of its programs or activities.

University policy also prohibits retaliation against any employee or person participating in any of ANR's programs or activities for bringing a complaint of discrimination or harassment pursuant to this policy. This policy is intended to be consistent with the provisions of applicable State and Federal laws.

Inquiries regarding the University's equal employment opportunity policies may be directed to Linda Marie Manton, Affirmative Action Contact, University of California Agriculture and Natural Resources, 2801 Second Street, Davis, CA, 95618-7774, 530-750-1318. For information about ordering this publication, telephone 1-800-994-8849.

To simplify information, trade names of products have been used. No endorsement of named or illustrated products is intended, nor is criticism implied of similar products that are not mentioned or illustrated.

An electronic copy of this publication can be found at the ANR Communication Services catalog website, http://anrcatalog.ucanr.edu/.

UC This publication has been anonymously peer reviewed for technical accuracy by University of California scientists and other qualified professionals. This review process REVIEWED was managed by ANR Associate Editor for Land, Air, and Water Sciences, Toby O'Geen.

web-5/14-LR/WS 